\title{
Ensalades en clausura: \\ Una primera aproximació als cançoners del convent de les carmelites descalces de Santa Teresa de Vic*
}

\author{
Ensaladas in the cloister: \\ A first approach to the songbooks of the convent of the Discalced Carmelites \\ of St. Teresa of Vic
}

\author{
Aurèlia Pessarrodona \\ aurelia.pessarrodona@uab.cat
}

Universitat Autònoma de Barcelona

\begin{abstract}
Resum: La recent troballa de dos cançoners al convent de Santa Teresa de Vic, datables al segle XVII, ve a ampliar i enriquir de manera considerable el que ja se sabia sobre la creació literària conventual i la presència de música, cants i altres manifestacions performatives dins de la clausura del Carmel descalç femení durant l'Edat Moderna. En aquest article es fa una primera aproximació a aquests cançoners, que posa de manifest les diferències entre ambdós: un recull repertori forà més antic, del segle XVI i inici del XVII, entre el que hi destaca la curiosa presència de moltes de les ensalades editades per Mateu Fletxa el Jove a Praga l'any 1581; i l'altre és un excel lent exemple de la creació literària de les pròpies monges, amb obres que abarcarien tot el segle XVII i inicis del XVIII. A més de descriure els manuscrits i apropar-se al seu contingut situant-lo en el seu context, en el present article es reflexiona sobre la possible praxi performativa del repertori, especialment sobre les ensalades.
\end{abstract}

Paraules clau: carmelites descalces, clausura, cançoners, ensalades, Mateu Fletxa

Abstract: The recent finding of two songbooks in the convent of Saint Therese in Vic (Barcelona), dated to the 17 th century, broadens and enriches strikingly what was already known about the literary creation in monasteries and performative manifestations — music, theater, dance — in the enclosed life of female discalced Carmel during the Modern Age. This article provides a first approach to these songbooks, that shows significant differences between them. The first one collects a foreign and older repertory, from 16th and early 17th centuries, that includes the unusual presence of ensaladas edited by Mateu Fletxa the Youger in 1581. The other one is an excellent example of literary creation of the nuns, with works dated from 17th to early 18 th century. As well as a description of the manuscripts, an approximation to their content and placing them in their context, the article includes some reflections concerning the performative practice of this repertory, above all of the ensaladas.

Keywords: discalced carmelites, cloister, songbooks, ensaladas, Mateu Fletxa

\footnotetext{
* Aquest treball s'ha realitzat gràcies a un ajut postdoctoral «Juan de la Cierva” (Incorporació) per treballar al Departament d'Art i Musicologia de la Universitat Autònoma de Barcelona. Agraeixo l'ajuda rebuda per part, sobretot, de Mercè Gras, que m’ha facilitat tot tipus de material i d'informació sobre la vida conventual del Carmel descalç femení; però també de col•legues que, de manera més indirecta, s'han implicat en aquest treball, com Verònica Zaragoza, Tess Knighton, Ascensión Mazuela Anguita i Marc Sogues. També ha estat molt important la informació proporcionada per María José Ruiz Mayordomo i Peio Otano sobre els aspectes coreològics, i per José Antonio González Valle, Luis Antonio González Marín i Antonio Ezquerro sobre la música a la Saragossa del Barroc. I, per descomptat, agraeixo amb especial afecte l'acolliment de les monges del convent de Santa Teresa de Vic.
} 
Aurèlia Pessarrodona. Ensalades en clausura: Una primera aproximació als cançoners del convent de les carmelites descalces de Santa Teresa de Vic

\begin{abstract}
Mirar lo que se dize en el coro assí cantado, como rezado, que sea en voz baxa, conforme a nuestra professión, que edifique. Porque en yr altas ay dos daños; el uno, que parece mal, como no va por punto; el otro, que se pierda la modesta, y espíritu de nuestra manera de vivir (Teresa de Jesús 1613).
\end{abstract}

D’aquesta manera Santa Teresa de Jesús descrivia com havia de ser el cant dins de la reforma carmelitana que ella va impulsar. Degut a aquesta cita es podria creure que la praxi musical en el Carmel descalç durant l'Edat Moderna era molt escassa i excepcional. No obstant això, ja fa temps que està assumit que la realitat era força diferent, com ho testimonien diversos cançoners trobats en convents de monges carmelites descalces: els de Valladolid i Medina del Campo estudiats als anys vuitanta (García de la Concha i Álvarez Pelliter 1982; Álvarez Pelliter 1983); els casos més recents d'Úbeda (Morales Borrero 1993) i Barcelona (Zaragoza, en prensa), i fins i tot de l'àrea de França i Països Baixos (Hanna 2015). Aquests cançoners posen de manifest la notable presència de la música en els convents del Carmel descalç femení, normalment en l'entorn de les recreacions — moments d'esbarjo social de les religioses — i sovint lligada a una pràctica d'escriptura poètica realitzada per les pròpies monges.

És més que possible que aquests cançoners siguin tan sols la punta d'un iceberg molt més ampli, com ho indicaria la recent troballa a l'Arxiu de les Carmelites Descalces de Vic (= ACDV) de quatre manuscrits amb una alta presència de poesia lírica vinculada a la pràctica musical dins del convent de Santa Teresa d'aquesta ciutat durant el segle XVII. ${ }^{1}$ Tots són datables durant el segle XVII i podrien estar relacionats amb els primers anys de funcionament del convent, fundat l'1 de gener de 1638 per iniciativa de les vigatanes Esperança Pradell i Maria Osona —qui esdevingué la mare Maria de les Llagues_- amb quatre monges provinents del convent de Santa Teresa de Saragossa (Beltran 1990: 163-180).

L'objectiu d'aquest article és descriure aquest material i apuntar alguns aspectes que se'n deriven de cara a incentivar estudis posteriors. Donada la magnitud de la troballa, aquest treball se centra en els dos primers manuscrits, veritables cançoners que esdevenen excel lents exemples de la pràctica tant d'escriptura com musical, teatral i fins i tot corèutica de la vida conventual; en canvi, els altres dos presenten un nombre considerablement menor de textos poètics o poètico-musicals. ${ }^{2}$ En els apèndix es troba la descripció del contingut dels dos cançoners objectes d'aquest estudi. 1. E1 Ms.

1 La troballa dels manuscrits l'ha realitzat la Mercè Gras, a qui agraeixo profundament que els posés al meu abast per tal de poder-los estudiar.

2 Els dos manuscrits que queden al marge d'aquest article presenten una enquadernació en pergamí en bastant mal estat. Un d'ells medeix 145 x 110 mm, té 199 f. numerats i a partir del f. 194v està en blanc. L'altre medeix 205 x 145 mm, té 17 f. s.n. +21 f. numerats +122 f. s.n. +1 f. en blanc. Contenen alguns textos poètics juntament amb d'altres de caire assagístic i espiritual com Avisos que dexo escritos para sus monjas la venerable Madre Isabel de Santo Domingo, Exortaciones que dexo escritas de su pròpia mano la madre Francisca de Jesús, Exercicio interior y pres ${ }^{a}$ de dios Real Imag ${ }^{a}$ int $^{a}$ y unitiva o Exercisio espiritual del Padre Fray Fran ${ }^{c h}$ del Sant ${ }^{\circ}$ Sacro.

SCRIPTA, Revista internacional de literatura i cultura medieval i moderna, núm. 7 / juny 2016 / pp. 187 - 219 ISSN: 2340-4841 $\cdot$ doi:10.7203/SCRIPTA.7.8476 
Aurèlia Pessarrodona. Ensalades en clausura: Una primera aproximació als cançoners del convent de les carmelites descalces de Santa Teresa de Vic

\section{1: «E1 cançoner de les ensalades»}

Aquests cançoners encara no tenen cap signatura ni topogràfic dins de l'ACDV, de manera que els anomenarem, de manera provisional, Ms. 1 i Ms. 2. El Ms. 1 medeix 150 x 107 mm, té 2 f. [índex] + 107 f. numerats +28 f. s.n., i està enquadernat en pergamí en mal estat, reaprofitant un antic cantoral, amb lletres en tinta vermella. És datable durant la primera meitat del segle XVII.

Es desconeix la procedència d'aquest cançoner. Es podria sospitar que el portés alguna de les monges saragossanes que van fundar el convent el 1638 i més tard s'hi afegissin els últims textos, escrits per altres mans. No obstant això, alguns trets suggereixen un origen català, com el fet d'incloure cançons amb text en català — les follies del núm. 8 i les cobles de Santa Caterina del núm. 45-, i la presència d'una marca d'aigua similar a altres localitzades per la zona d'Osona i Olot (Valls 1970: I, 391-392; II, 221), i que no consta en les bases de filigranes de la zona de Saragossa. ${ }^{3}$ Tanmateix, no s'ha pogut identificar cap de les cal ligrafies, que no coincideixen amb les de les monges de Vic. ${ }^{4}$

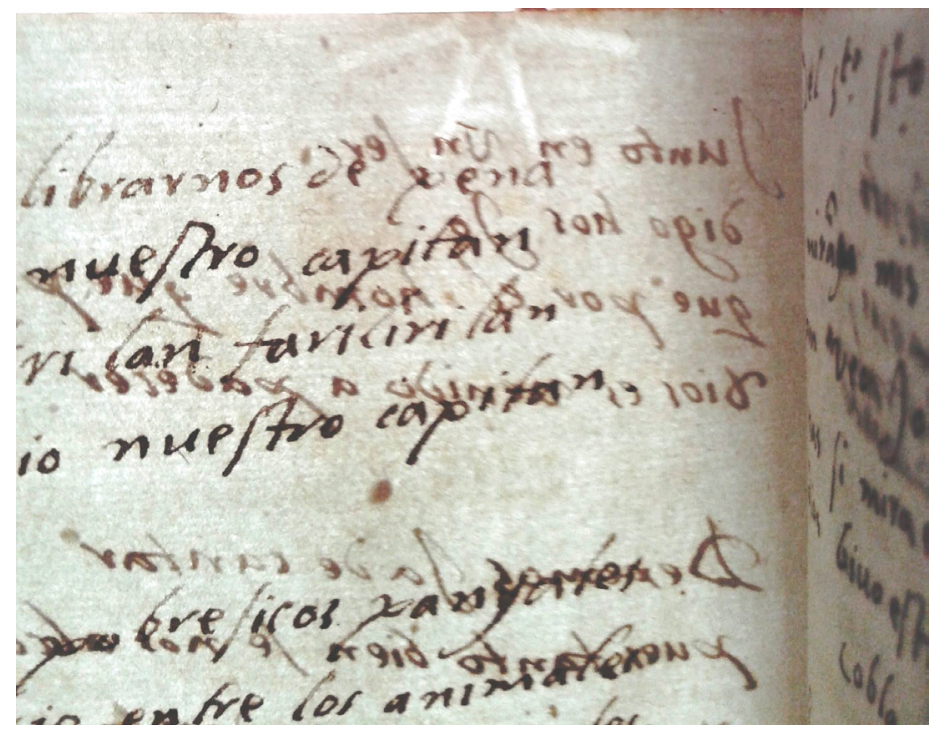

Figura 1: Detall del f. 38v del Ms. 1 del Convent de Santa Teresa de Vic amb la marca d'aigua.

A grans trets, podem distingir tres grans grups obres que correspondrien a diverses etapes d'escriptura: un primer grup que abarca fins el núm. 24, que correspon a les peces que apareixen indicades en els índex de les primeres pàgines; un segon grup fins el núm. 51, amb la mateixa cal ligrafia que l'anterior; i un tercer grup, del núm. 52 al 56, amb obres afegides per altres tres mans, sense foliar.

\footnotetext{
3 Filigranas en la provincia de Zaragoza, consultable online: <fil.dpz.es $>$.

4 Els documents usats per al coteig són els de les professions, que es troben en la Breve relación de la vida edificante de algunes religioses de esta Comunidad (= Breve relación...), ACDV, sense signatura, està reproduit a l'Arxiu General dels Carmelites Descalços de Catalunya i Balears com Vic, Carmelites Descalces: Fundacions, professions, òbits, eleccions, 1637-1770. En aquest treball utilitzo la paginació actual, afegida a llapis, d'aquesta còpia.
} 
Aurèlia Pessarrodona. Ensalades en clausura: Una primera aproximació als cançoners del convent de les carmelites descalces de Santa Teresa de Vic

\subsection{Les ensalades}

Pel que fa al primer grup d'obres, els índex de les primeres pàgines expliciten les temàtiques i els gèneres de la forma següent: «Canciones del Nacimiento de Christo» (núms 1, 5, 7 i 9); «Ensaladas a lo divino» (núms 2, 4, 6, 8, 10, 12, 14, 16, 18, 20, 22); «Del Santissimo Sacramento» (núms. 11, 13, 15, 17, 19, 23 i 24); i «Canciones a Nuestra Senyora» (núms. 3 i 21). Corresponen, per tant, a part de les temàtiques habituals que constituien els principals cicles dels cançoners carmelitans descalços coneguts i que sí que trobarem en el Ms. 2: el Nadal, les festivitats i devocions, el Santíssim Sacrament, la Verge Maria, Sants o hagiogràfic, hàbits o vels, els aspectes de la vida religiosa, la recerca de la unió de l'ànima de l'Esposa amb l'Amat Déu (García de la Concha i Álvarez Pellitero 1982: II, xix-xxi; Zaragoza, en premsa). ${ }^{5}$ L'última obra d'aquesta part correspon a un Auto sacramental de la fe, una breu obra de teatre de procedència desconeguda protagonitzada per l'Entendimiento, la Fe, la Razón i la Ignorancia; i que finalitza amb un breu vilancet de tres versos, que serveix per acabar el primer bloc de manera teatral.

Les veritables protagonistes d'aquest primer grup de peces són les ensalades: gairebé tota aquesta part està formada per ensalades intercalades amb altres obres. No és estranya la presència d'ensalades en cançoners del segle XVII. Segons Kruger-Hickman (1984, apud Tenorio 1999: 149-151), el gènere de l'ensalada va néixer cap a mitjans del segle XV i va perdurar fins la primera meitat del XVII; i distingeix entre tres tipus d'ensalades: 1) una molt rudimentària en la qual el text narratiu és més extens que els textos intercalats — normalment tornades de vilancets populars-; 2) les ensalades tipus Fletxa, que abarquen gairebé tot el segle XVII, i que són composicions extenses, de caire més aviat al legòric, en què hi predominen els temes religiosos i on el diàleg té major presència; i 3) un tipus d'ensalada que Krugel-Hickman anomena «pre-barroca» $\mathrm{O}$ «escènica», que tendeix a utilitzar tirades de romanços i a presentar escenes festives rústiques, amb abundància d'acudits populars i intercalació de vilancets. ${ }^{6}$ De fet, Gómez Muntané (2008: I, p. 91) considera que durant el segle XVII «el género se confunde con el del villancico, lo que supone un regresso a sus orígenes, hasta el punto de que se hace difícil diferenciarlos». Un bon exemple musical d'ensalada del segle XVII és la que apareix en els Romances y letras de a tres voces de la Biblioteca Nacional (Lambea 1997). També tenim exemples d'ensalades poètiques entre les obres dels escriptors Alonso de Ledesma, Alonso Bonilla i José de Valdivielso, tal com podem observar en la «Ensaladilla del Retablo» d'aquest últim inclós més endavant en aquest mateix cançoner (núm. 50). ${ }^{7}$

5 És un tema que Zaragoza ha tractat amb molta major profusió en la seva tesi doctoral, encara inèdita, «"En vers vull desafiar...”. La poesia femenina a l'àmbit català (segles XVI-XVII). Edició crítica», Girona: Universitat de Girona, Facultat de Lletres, 2016.

6 Martha Lilia Tenorio (1999: capítol VI) afegeix una quarta etapa de major barroquització del gènere amb la combinació d'elements de les ensalades de González de Eslava (ca. 1534-ca. 1601) i de Góngora (1562-1627), però que es va desenvolupar sobretot a Latinoamèrica.

7 L'obra descriu una representació, en el Corral de la Cruz de Madrid, d'un espectacle de titelles titulat El retablo de la entrada del Rey pobre, de temàtica nadalenca, on no hi mancava la tradicional escena còmica de l'adoració dels pastors (Varey 1979: 157-160).

SCRIPTA, Revista internacional de literatura i cultura medieval i moderna, núm. 7 / juny 2016 / pp. 187 - 219 ISSN: $2340-4841 \cdot$ doi:10.7203/SCRIPTA.7.8476 
Aurèlia Pessarrodona. Ensalades en clausura: Una primera aproximació als cançoners del convent de les carmelites descalces de Santa Teresa de Vic

El que sobta en aquest cas és que estem davant d'un cançoner segurament de la primera meitat del segle XVII però amb textos d'ensalades d'un segle abans sense la música. De fet, són pràcticament totes les ensalades del volum publicat per Mateu Fletxa el Jove a Praga l'any 1581 (Fletxa 1581; vegi's l'estudi i l'edició crítica de Gómez Muntané 2008); només hi manquen La Viuda de Mateu Fletxa el Vell, les dues versions de Las Cañas dels dos Fletxes, i Ben convenne, madrigal profà de Mateu Fletxa el Jove; és a dir, les obres menys religioses del recull.

Tot i que falta un estudi més profund, semblaria que el/la copista anònim/a coneixia les obres polifònicament, potser per haver-les escoltat o interpretat, tal com ho mostra la separació de les diferents seccions amb major espaiat i en l'escriptura dels versos tenint en compte totes les veus, com és el cas de l'inici de la segona part de l'ensalada El Fuego (Fig. 2), en què el primer vers correspon a l'inici del cantus i del tenor i les onomatopèies «dan, dan, dan, etc.» al de l'altus i el bassus. El text podria haver estat copiat de l'edició de Praga, però s'hi troben diferències en les grafies, potser per influència «catalana», com s'observa en el «venit» d'aquesta mateixa pàgina en lloc del «venid» original.

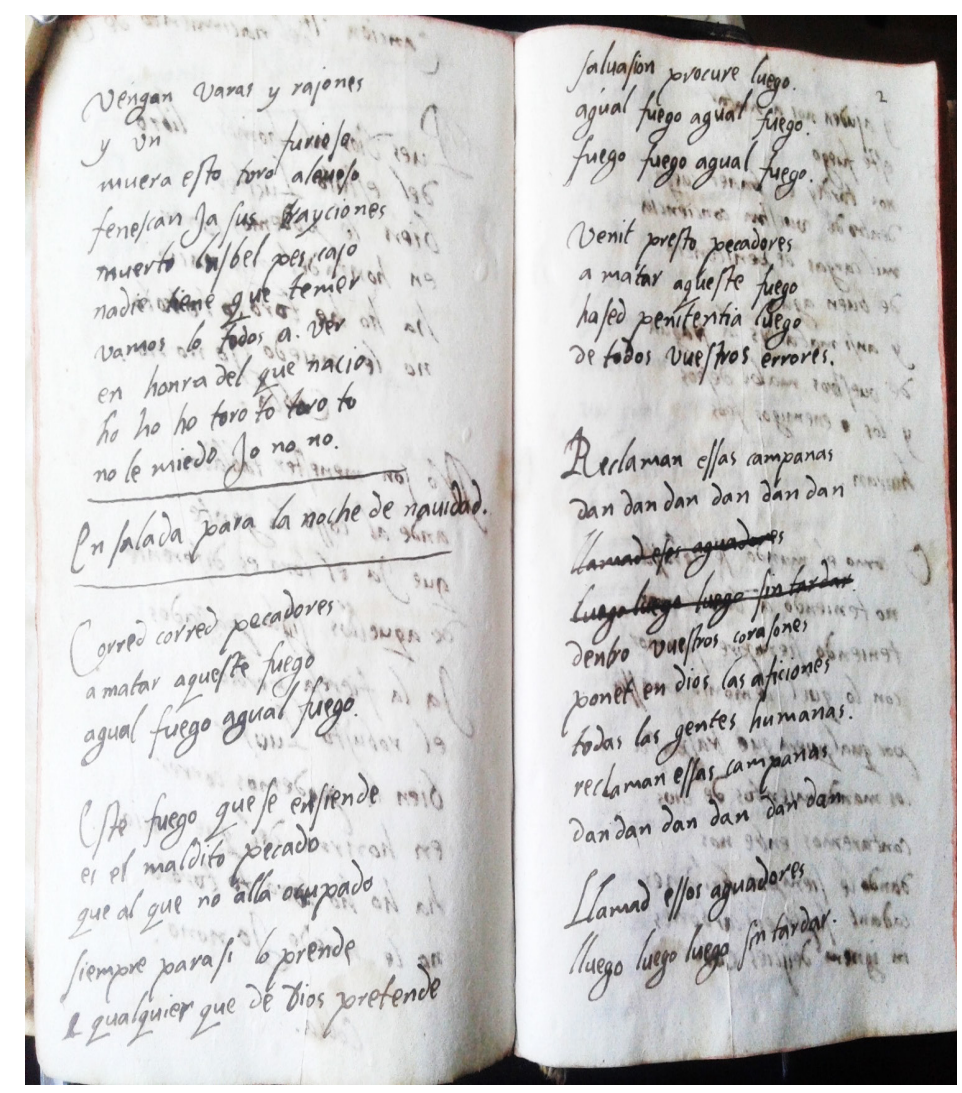

Figura 2: f. 2r del Ms. 1 del convent de Santa Teresa de Vic 
Aurèlia Pessarrodona. Ensalades en clausura: Una primera aproximació als cançoners del convent de les carmelites descalces de Santa Teresa de Vic

L'autor més representat és Mateu Fletxa el Vell, amb sis ensalades que, segons la cronologia proposada per Gómez Muntané (2008: I, 77-78), foren compostes entre 1524/ 5 i 1532/3, és a dir, un segle abans de la fundació del convent vigatà de Santa Teresa. Altres compositors del recull són Càrceres i Chacón, de biografia molt més fosca però coetanis a Fletxa el Vell. L'única ensalada de Mateu Fletxa el Jove, La Feria, pertany a una generació posterior, però és deutora estilísticament de les del seu oncle. Per tant, en general es tractaria d'un repertori força allunyat dels gustos que imperarien a mitjan segle XVII.

D’altra banda, la inclusió de dues ensalades de Pere Vila, Bon jorn (Alberch Vila 1983) i La Lucha, podria tenir algun vincle amb l'entorn vigatà del convent. Tot i que normalment s'ha considerat Pere Alberch Ferrament, àlies Vila, com a compositor d'aquestes ensalades, Gómez Muntané planteja la possibilitat de que fossin obra del seu oncle, Pere Vila, que, de fet, és el nom que apareix a l'edició de Praga. Ambdós, oncle i nebot, pertanyien a la nissaga vigatana dels Vila, organistes, compositors i orgueners de renom almenys durant un segle i mig (Gregori 1986-87).

Pere Vila, el fundador de la nissaga, va néixer a Vic l'any 1465 i bona part de la seva carrera va estar vinculat a la catedral d'aquesta ciutat, primer com a organista —abans de 1516 i fins 1528i després com a canonge — des de novembre de 1519—. En possessió de diversos beneficis a la catedral de Barcelona, va ser organista de la de València almenys entre 1534 i 1538, any de la seva defunció. Des de València Vila va gestionar l'adquisició de la titularitat de la plaça d'organista de la catedral de Barcelona al seu nebot Pere Alberch i els seus possibles descendents, a canvi de la donació de sis-cents ducats d'or destinats a restaurar l'orgue barceloní (Gregori 1986-87: 50-55; 1987: cap. VII).

L'abril de 1536 Pere Alberch Ferrament, àlies Vila, nascut a Vic el 1517, es va convertir en organista de la catedral de Barcelona gràcies a les gestions del seu oncle, a qui devia haver vist personalment en dos viatges que va realitzar a València, el primer l'any $1537 \mathrm{i}$ el segon a principis de l'any següent. Va ser anomenat canonge de la seu barcelonina el desembre de 1558 i va gaudir d'un important nombre de beneficis en diferents institucions eclesiàstiques catalanes, la major part dels quals li van ser concedits entre 1560 i 1577. El juliol de 1580 el capítol de la catedral de Barcelona va anomenar ajudant seu al seu nebot, Lluís Ferran Ferrament. Després de la mort de Pere Alberch, el 16 de novembre de 1582, el va succeir el seu nebot (ibid.: 23; Gregori 1986-87: 50 i 60).

Segons Gómez Muntané, seria més versemblant que les ensalades de l'edició de Praga fossin del primer Vila, donat el seu vincle amb València. Tal com diu, «El contexto valenciano resulta, en principio, más sugestivo que el de Barcelona para este tipo de composiciones» (Gómez Muntané 
Aurèlia Pessarrodona. Ensalades en clausura: Una primera aproximació als cançoners del convent de les carmelites descalces de Santa Teresa de Vic

2008: I, 25). ${ }^{8}$ Això ho corroboraria el fet que el volum anés dedicat a Joan de Borja, III duc de Gandia, mecenes de Fletxa el Jove i important promotor cultural i musical (Escrivà Llorca 2015: 154-155). Però, tal com s'ha apuntat recentment, ja feia temps que existia una estreta connexió entre Gandia i Saragossa (id. 2007: 14-16). Per exemple, sembla que Bartomeu Càrceres havia estat treballant a la zona aragonesa abans de 1546 (id. 2015: 23).

Així, doncs, no es pot descartar que les monges saragossanes haguessin tingut accés a aquest repertori o a algun de similar. Cal tenir en compte que el convent d'origen, el de Santa Teresa de Saragossa, fou fundat el 1623 per Diego Fecet per albergar religioses filles de notaris de número de la ciutat, de manera que haurien rebut una instrucció alta com corresponia al seu estatus social i cultural. ${ }^{9}$ Entre aquestes primeres monges saragossanes hi havia Francisca de San Agustín, de Gotor (Tauste, ? - Tarazona, 1642), qui podria haver tingut alguna relació de parentesc amb Pedro de Gotor, canonge de la catedral de Tarazona a principis de segle. ${ }^{10}$ En aquesta catedral hi havia una nombrosa col lecció d'ensalades, tal com ho indiquen uns inventaris dels fons musicals d'aquesta seu de 1570 i 1591, però les obres dels quals malauradament s'han perdut (Calahorra 1992, Gómez 2008: I, 39-42).

8 Gómez Muntané (2008: I, 25) les explica de la manera següent: «De las otras cuatro ensaladas que fray Mateo Flecha incorporó a la edición de Praga, aparte de las suyas, la de Cárceres en principio debe vincularse al contexto valenciano, teniendo en cuenta, entre otros factores, que su autor servía en 1546 en la capilla del duque de Calabria y que tiempo después fijó su residencia en Gandía. El contexto de la de Chacón, riguroso contemporáneo de Flecha el Viejo que como él fue maestro de capilla en la catedral de Sigüenza, podría coincidir con el de alguna de las ensaladas de Flecha. En cuanto a las de Vila, si se trata de la persona que ejerció como organista de la catedral de Valencia cuando Flecha el Viejo, a la sazón maestro de capilla de la de Sigüenza, acaso recibió un beneficio en la Iglesia valenciana de San Lorenzo, su contexto sería de nuevo Valencia. Si se trata en cambio de su sobrino, que falleció al año de haber aparecido la edición de Las Ensaladas, son varias las cuestiones que se derivan de las dos obras del género que se le atribuyen, empezando por la de dónde y cuándo Flecha el Joven tuvo ocasión de hacerse con una copia. Los viajes que Alberch Vila realizó a Valencia entre 1537 y 1538, a los veinte o veintiún años, cuando Flecha el Joven aún era un niño, lo más probable es que obedeciesen a cuestiones familiares. Después ni Alberch Vila parece haberse movido del territorio catalán ni Flecha el Joven parece haber residido en Cataluña, salvo de niño y a partir de 1600/1, que es cuando se retiro al monasterio de La Portella». De totes formes, si tenim en compte que Pere Alberch consta a la catedral de València entre 1533 i 1536 com a alumne de l'organista, el seu oncle (Villanueva 2009: 96-97), el vincle del músic amb aquesta ciutat no semblaria tan esporàdic. Sobre les relacions musicals entre Barcelona i València, vegi’s Gregori (2004).

9 Per exemple, Mercè Gras m’informà del parentesc directe entre la religiosa Gertrudis de San José, Andrés Pérez (? - 1642) amb una de les famílies més importants de Saragossa, els Ustarroz: era filla de Baltasar Andrés de Ustarroz, catedràtic de dret a la Universitat de Saragossa (1597-1602), i d’Isabel Pérez Díez de Aux, i nét de Jerónimo Andrés de Ustarroz, diputat d'Aragó (1588) i jurat de Saragossa. Per tant, fou germana de Juan Francisco Andrés de Ustarroz, cronista d'Aragó, i de Jerónimo Andrés de Ustarroz, monjo de Sant Joan de la Penya i prior d'Estella (Zaragoza 2004: 317). Gras té previst aprofundir en aquesta línia en un proper article sobre la noblesa aragonesa i el Carmel descalç.

10 Va ser chantre de la catedral el 1600 i consta que va acompanyar les monges que sortiren de Tarazona per fundar l'ardiaconat de Calatayud (Gracián 1919: 26).

SCRIPTA, Revista internacional de literatura i cultura medieval i moderna, núm. 7 / juny 2016 / pp. 187 - 219 ISSN: 2340-4841 · doi:10.7203/SCRIPTA.7.8476 
Aurèlia Pessarrodona. Ensalades en clausura: Una primera aproximació als cançoners del convent de les carmelites descalces de Santa Teresa de Vic

De totes formes, el fet que el cançoner inclogui obres d'un membre de la nissaga vigatana dels Vila podria explicar la presència d'aquestes ensalades en un convent de clausura de Vic. De fet, el volum presenta una altra obra d'un d'aquests compositors de la nissaga, el madrigal espiritual de Pere Alberch Vila Cuando contemplo en ti, Virgen María (núm. 21), que va incloure a la segona part del seu volum Odarum (quas vulgo madrigales appellamus), publicat a Barcelona el 1561 (Alberch Vila 1561). No seria l'únic cas en què aquest madrigal apareix en un volum junt amb ensalades, ja que també el trobem al Ms. 588/2 de la Biblioteca de Catalunya, una antologia musical de vuit ensalades i dotze madrigals possiblement copiada en terres de l'antiga Corona d'Aragó de parla catalana (Gómez Muntané 2008: I, 35).

A més, entre la relació de monges del convent en trobem almenys dues que, pels cognoms, pogueren formar part de la família de músics. Una és Isabel de l'Esperit Sant, Berguedà Bover (1647-1683), de Vic, que rebé la vestició el 21 d'octubre de 1663 i professà el 28 d'octubre de $1664 .{ }^{11}$ Era filla de Joan Francesc Berguedà, natural de Vic, i Maria Bover, de Ripoll, i potser serien descendents de la branca dels Berguedà emparentats amb els Ferrament per via política (Gregori 1986-87: 74). L'altra és Maria Rosa de Jesús, Alberch Pujol (1682-1736), que ingressà el 21 de gener de 1702 i professà just un any després. ${ }^{12}$ Era natural de Vic, filla de Josep Alberch i Comolada, també de Vic i potser relacionat amb els Alberchs músics, i Eulàlia Pujol, de Granollers. De totes formes, les dates de vestició i professió d'ambdues monges semblen massa tardanes com per vincular-les amb el cançoner.

\subsection{Algunes reflexions sobre possibles praxis executives}

Aquest manuscrit desperta moltes incògnites sobre quina seria la funció d'aquestes ensalades dins de la vida quotidiana del convent de Santa Teresa de Vic. De què serviria tenir els textos copiats d'aquestes obres? Encara s'interpretarien? En cas afirmatiu, ¿'serien les mateixes monges les que cantarien les ensalades de memòria $— \mathrm{O}$ amb alguna còpia de l'edició de Praga— o els textos servirien per tal que les monges poguessin seguir — i potser recordar — interpretacions d'alguna capella forània? ¿ $\mathrm{O}$ aquests textos serien testimonis de pràctiques improvisatòries sobre cançons conegudes?

Si ens cenyim a la música coneguda d'aquestes ensalades, no són en absolut obres fàcils i hi predominen les tessitures greus. Per tant, necessiten intèrprets masculins, llevat que les veus greus fossin realitzades per instruments. En aquest sentit pot tenir-se en compte el que comenta

11 ACDV, Breve relación..., p. 111. Sobre aquesta monja, vegi's l'entrada corresponent al Diccionari d'autors $i$ obres de religiosos carmelites descalcos (Gras 2013b).

12 ACDV, Breve relación..., p. 166.

SCRIPTA, Revista internacional de literatura i cultura medieval i moderna, núm. 7 / juny 2016 / pp. 187 - 219 ISSN: $2340-4841 \cdot$ doi:10.7203/SCRIPTA.7.8476 
Aurèlia Pessarrodona. Ensalades en clausura: Una primera aproximació als cançoners del convent de les carmelites descalces de Santa Teresa de Vic

González Marín sobre la pràctica musical en convents carmelitans, concretament al voltant del compositor portuguès Manuel Correa (ca. 1600-1653), carmelita calçat — com Fletxa el Jove_, ${ }^{13}$ mestre de capella de la catedral de Saragossa a partir de 1650 i que va compondre obres per a monges carmelites, tot i que no s'especifica de quin convent ni quin orde:

\begin{abstract}
(...) El villancico Tras de un amoroso lance, de fray Manuel Correa sobre un texto de Santa Teresa está compuesto a tres voces (dos tiples y tenor), con acompañamiento, escrito en una sola particela, de «arpa i biguela de arco», y presenta la particularidad de que las partes de tiple se destinan a sendes monjas carmelitas cantoras (Ynés y Vastida), como sucede en otras composiciones del autor, también carmelita. En su villancico a Santo Domingo Esa estrella que ves, destinado a la misma capilla de monjas carmelitas, encontramos una particella de bajo con el siguiente texto: «bajo biguela de arco y banjon [sic] grande si le ubiere», a la vez que, en la parte de tenor, se indica que se tocarà con bajoncillo tenor en caso de que la cantora $-\mathrm{D}^{\mathrm{a}}$ Beatriz de Mendoza - no pueda cantar una parte tan grave (González Marín 1997: 108).
\end{abstract}

El cas que exposa González Marín té la particularitat de que es tracta d'un repertori fet expressament per a les qualitats vocals d'unes monges concretes; però serveix per constatar que, en el cas que les religioses no poguessin cantar en aquelles tessitures, ho interpretarien instruments, sobretot de vent.

No tenim documentació explícita sobre la formació musical de les monges carmelites de Vic, però sí que coneixem notables monges músiques en altres convents de la mateixa província carmelitana, la de Sant Josep de Catalunya. Mercè Gras (2013a: 318; 2015) documenta diversos casos de monges amb notables dots musicals en el convent de la Puríssima Concepció de Barcelona: per exemple, Maria Ramon Ayllà (ca.1629-1705), que aprofità el seu talent com a arpista per entrar en el convent, professant-hi com a Maria de Jesús l'any 1648; o la noble Beatriu de l'Encarnació, de Borbó i Roger (1600-1637), que, segons el Libro de difuntas, es distingia en la interpretació de «música de manacor o espinete y guitarra, y a lo mejor la voz, que yo en los días de mi vida he ohido de mejor y gargantilla más clara y delicada». De fet, aquesta formació musical li va permetre dirigir el cor conventual; tal com afirma el frare Anastasio de Santa Teresa (1739: VII, 553; apud Gras 2015): «Tenía muy clara y meliflua y corpulenta voz, con la que governava el coro, y hazía menos gravosos los oficios divinos». ${ }^{14} \mathrm{Cal}$ tenir en compte que les noies que acreditaven saber tocar l'orgue o tenir coneixements musicals i poder impartir lliçons de cant a les religioses podien veure rebaixat el dot o fins i tot no haver-lo de pagar (Gras 2013a: 318; 2015).

En canvi, sí que s'ha pogut documentar la presència de músics al convent de Santa Teresa de Vic que ajudarien en certs oficis ja des dels primers anys d'existència del convent, tal com quedà

13 Tot i que al final de la seva vida va canviar l'orde, esdevenint abat del monestir de La Portella de Solsona, on va morir cap a 1604 (Gómez Muntané 2008: I, 18-21).

14 Resulten curioses les descripcions contradictòries de la veu d'aquesta religiosa, ja que una «gargantilla clara y delicada» difícilment encaixa amb una veu «corpulenta».

SCRIPTA, Revista internacional de literatura i cultura medieval i moderna, núm. 7 / juny 2016 / pp. 187 - 219 
Aurèlia Pessarrodona. Ensalades en clausura: Una primera aproximació als cançoners del convent de les carmelites descalces de Santa Teresa de Vic

registrat al llibre de despeses dins de l'any $1638:^{15}$

1 de gener: «de los músicos $\mathrm{q}^{\mathrm{e}}$ cantaron el dia $\mathrm{q}^{\mathrm{e}}$ se puso el $\mathrm{S}^{\text {mo }} \mathrm{S}^{\text {to }}$ $51100 \mathrm{~s} »$

Abril: «di a los $\mathrm{q}^{\mathrm{e}}$ cantaron La pasion la semana $\mathrm{s}^{\text {ta }}$ $01118 \mathrm{~s} »$ Juny: «mas de los musicos $\mathrm{q}^{\mathrm{e}}$ cantaron la octaba del $\mathrm{S}^{\text {mo }} \mathrm{S}^{\text {to }}$ $41116 \mathrm{~s} »$ Juliol: «mas de los $\mathrm{q}^{\mathrm{e}}$ cantaron la fiesta de $\mathrm{N}^{\text {tra }} \mathrm{S}^{\text {ta }}$ del abito $31110 \mathrm{s»}$

Dins de l'any 1639:

Diumenge 31 de juliol: «de los musicos que cantaron en la fiesta de $\mathrm{N}^{\text {tra }} \mathrm{S}^{\text {ra }}$ del Carmen $11108 \mathrm{s»}$

Extraordinari del 30 de juny: «de los músicos que cantaron en la fiesta del SS ${ }^{\text {mo }}$

$\mathrm{S}^{\text {to }}$ tengo pagadas $3116 \mathrm{~s}$ y por olbido no lo puse en el mes pasado dich $3116 \mathrm{s»}$

Extraordinari del 31 d'octubre: «de los musicos que cantaron en la fiesta de $\mathrm{N}^{\text {tra }} \mathrm{S}^{\mathrm{a}}$

$\mathrm{M}^{\mathrm{e}}$ Teresa $21116 \mathrm{s»}$

Dins de l'any 1640:

Diumenge 10 de juny: «de la fiesta del santissimo sechremento a los musichos $31104 \mathrm{~s}\rangle$ Extraordinari de juliol: «de los musicos que cantaron en la fiesta de $\mathrm{N}^{\text {tra }} \mathrm{S}^{\text {ta }}$ les di $211 »$

Extraordinari d'octubre: «de los musicos $\mathrm{q}^{\mathrm{e}}$ cantaron en la fiesta de $\mathrm{N}^{\mathrm{a}} \mathrm{S}^{\mathrm{a}} \mathrm{M}^{\mathrm{e}}$ Theresa 41108 s»

Dins de l'any 1641:

Extraordinari de juny: «de los musicos que cantaron en la octaba del $\mathrm{S}^{\text {mo }} \mathrm{S}^{\text {to }}$ $21116 \mathrm{s»}$ Extraordinari de juliol: «de los musicos y sermon de la fiesta de $\mathrm{N}^{\text {a }} \mathrm{S}^{\mathrm{a}}$ del abito $31113 \mathrm{~s} »$

I dins de l'any 1642 només un extraordinari al juliol:

«Yten de la musica para la fiesta de Nra Sra del Abito $21116 \mathrm{s»}$

Tot plegat constata la presència de músics forans per intervenir en celebracions litúrgiques importants, sobretot a l'octava del Corpus, Setmana Santa, la Verge del Carme i Santa Teresa.

Curiosament, aquests pagaments no fan referència al Nadal, que seria quan s’interpretarien

15 ACDV, Libro de la tornera, sense signatura. 
Aurèlia Pessarrodona. Ensalades en clausura: Una primera aproximació als cançoners del convent de les carmelites descalces de Santa Teresa de Vic

aquestes ensalades. En el mateix cançoner s'indica que la majoria d'ensalades eren per a la Nit de Nadal. I sabem que, almenys a la segona meitat del segle XVI, les ensalades van ser molt populars per amenitzar les celebracions nadalenques. Tal com documenta José López-Calo (1963: I, 257-258), a la catedral de Granada hi consta una notable interpretació de «chanzonetas y ensaladas» en festivitats nadalenques durant els anys 1560-70, tot i que, malauradament, no es conserva la música d'aquestes obres a l'arxiu catedralici. Per exemple, dins dels Acords Capitulars granadins referents al Nadal es troba que a l'any 1565 «se disputaron para ver las chanzonetas y ensaladas y todo lo que se ha de decir a los señores doctor Pedraza y doctor Fonseca, juntamente con el señor Presidente»; «que se le den a Juan Ramos tres fanegas de la fàbrica por el trabajo de imponer a los seises en lo bailes de las ensaladas»; «que se libren a Gregorio Silvestre seis fanegas de trigo por el trabajo y ocupación de las chanzonetas y ensaladas de las fiestas de Navidad en la fábrica» i a l'any 1566 «a Gregorio Silvestre se le libren de capilla, otras doce fanegas de trigo por lo mismo» $\mathrm{i}$ «a Juan Ramos seis fanegas de trigo por el trabajo de imponer a los seises en los bailes de las ensaladas». Segons Gómez Muntané (2008: I, 81), aquestes interpretacions seguirien el costum — des de 1500 - de cantar i fins i tot ballar vilancets com a colofó del servei de laudes i a les matines del dia de Nadal, moment en què també es podien incloure peces dramatitzades de caire nadalenc.

Aquests testimonis de Granada posen de manifest la presència de la dansa dins de les ensalades, ballada pels seises de la catedral. Entre les ensalades d'aquest cançoner de Vic la dansa està present explícitament en dues d'elles: la dansa cantada de l'últim número de Los Chistes (núm. 16) i, sobretot, la pavana i la gallarda de La Trulla (núm. 6, descrita a la rúbrica com a «Ensalada mui graciosa»), danses de caire refinat i cortesà que solien interpretar-se conjuntament. Tal com s'observa a la Fig. 3 el/la copista anònim/a del manuscrit va indicar les danses de La Trulla amb les didascàlies «alto de la pavana» $\mathrm{i}$ « $[\mathrm{g}]$ allarda» als marges. Si bé la segona didascàlia indicaria que es canta i potser també es balla una gallarda, la primera pot tenir dues explicacions. Podria tractar-se d'una abreviatura de «al tono de la pavana», de la mateixa manera que altres peces inclouen el text «al tono de...» a la rúbrica per indicar la música amb la qual s'havien d'interpretar. En tenim bons exemples en aquest mateix cançoner, com és el cas de la Canción del santíssimo Sacramento, sobre y al tono de Caminad Señora (núm. 19). La cançó Caminad señora va ser molt popular als segles XV i XVI (Alín 1998: 151), i com a tal apareix recollida al De Musica libri septem de Francisco de Salinas (1577: 308) (Fig. 4). 
Aurèlia Pessarrodona. Ensalades en clausura: Una primera aproximació als cançoners del convent de les carmelites descalces de Santa Teresa de Vic

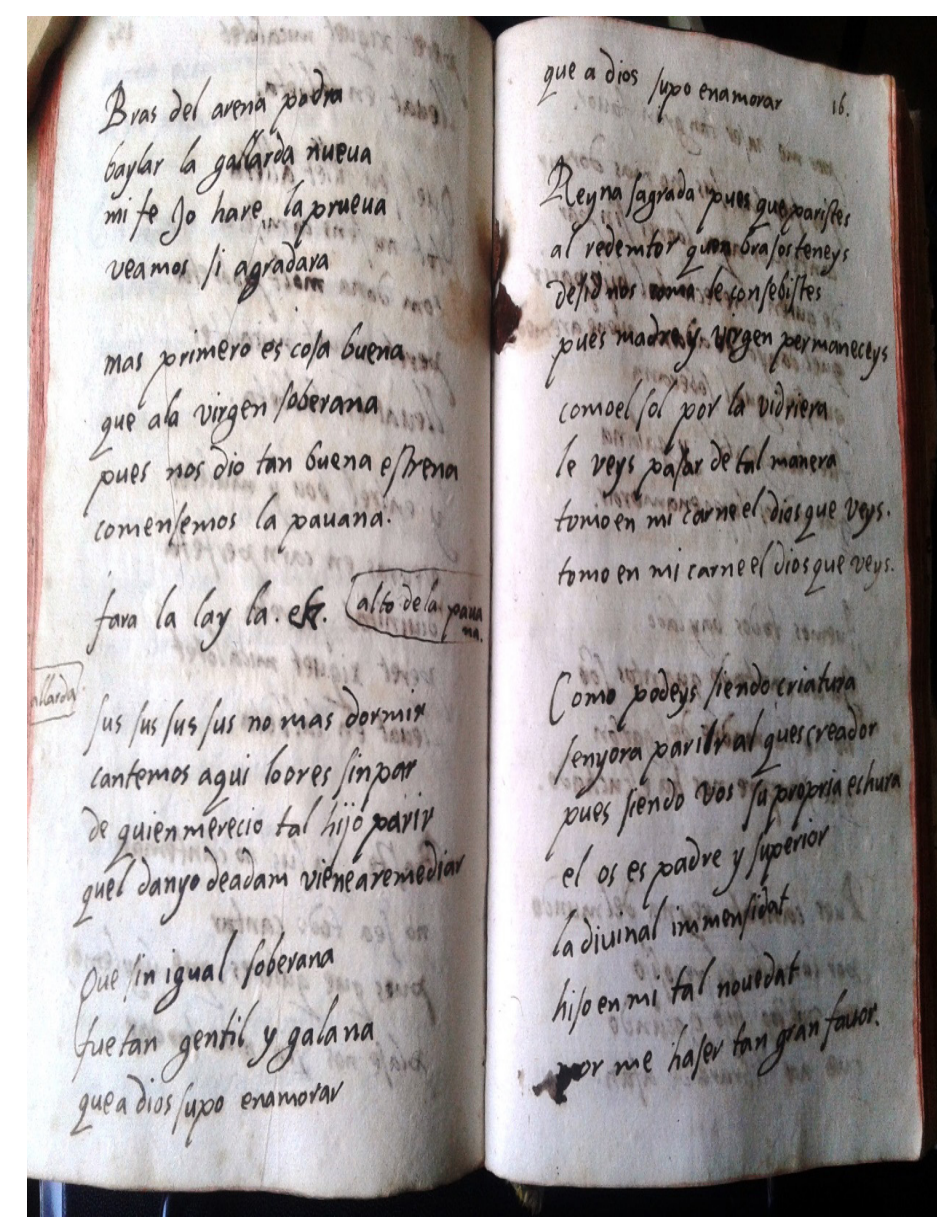

Figura 3: f. 15v del Ms. 1, amb text de l'ensalada La Trulla

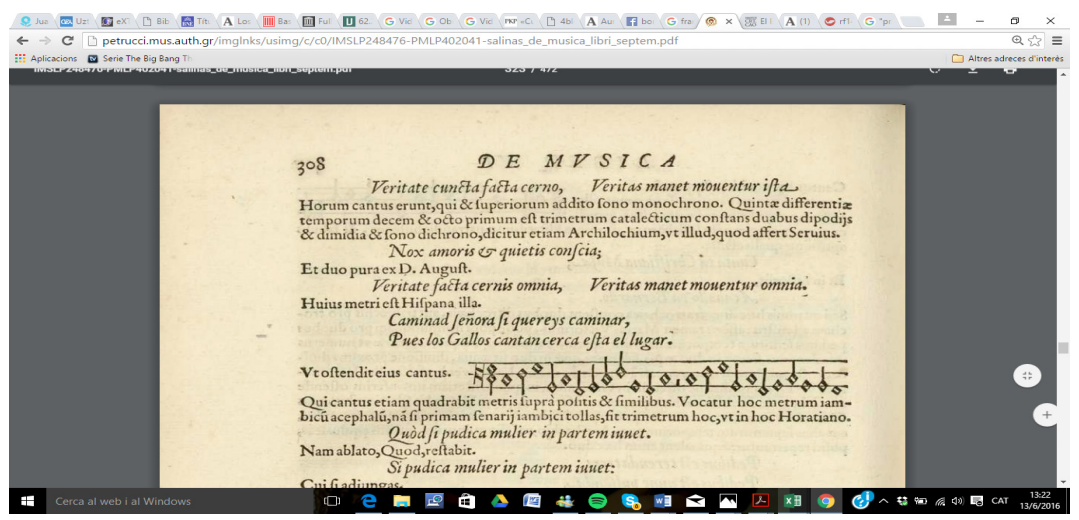

Figura 4: detall de la p. 308 de De Musica libri septem (1577) de Francisco de Salinas amb la melodia de la cançó Caminad señora. 
Aurèlia Pessarrodona. Ensalades en clausura: Una primera aproximació als cançoners del convent de les carmelites descalces de Santa Teresa de Vic

L'expressió «alto de la pavana» també podria fer referència a l'altus de la pavana com una melodia característica de la dansa. De fet, la música de Càrceres està construïda sobre un cantus firmus que apareix primer dues vegades en el tenor i tot seguit es repeteix dos cops al cantus (Fiorentino 2009: 202-204); en cap moment es dóna a l'altus, però la indicació potser serviria com a referència per recordar aquest cantus firmus.

En aquest sentit resulta molt interessant la reflexió de Fiorentino al considerar justament aquesta pavana - un contrapunt a quatre veus que imiten instruments amb onomatopeies - com a exemple d'imitació de la praxi improvisatòria instrumental sobre un cantus firmus. Els abundants «errors» de composició — nombroses dissonàncies, quintes i octaves paral leles- del número suggereixen que Càrceres «está imitando o parodiando algun tipo de estilo musical o una praxis ejecutiva de improvisación. (...). Cárceres quiso imitar un concerto instrumental semi-improvisado ejecutado por músicos no profesionales, o una forma de polifonia improvisada sobre un cantus firmus» (ibid.: 204). Qui sap si la didascàlia «alto de la pavana» del nostre cançoner faria referència a un cantus firmus conegut sobre el qual s'improvisava, realitzant el que Càrceres va voler imitar.

Aquest cas manifesta la possibilitat d'una praxi improvisatòria al voltant de les ensalades d'aquest cançoner, que segurament seria l'habitual en aquest tipus de cançoners sense la música escrita. La base compositiva principal d'aquestes ensalades és la paròdia de material anterior, tant textual com musical. Per exemple, la primera ensalada del manuscrit, El Fuego de Mateu Fletxa el Vell —que és precisament la que obre l'edició de Praga - conté un romanç especialment conegut, «Mira Nero de Tarpeya», que apareix en nombroses fonts des de finals del segle XV (Díaz-Mas 1985). Les ensalades són en bona part un calidoscopi de músiques i textos anteriors, segurament molt populars, refets i readaptats. Com afirma Gómez Muntané (ibid.: I, 77): «A pesar de que muchas de las cancioncillas, villancicos y romances que salpican las ensaladas de Flecha el Viejo hunden sus raíces en el pasado medieval, la mayoría de las veces sus elaborado tratamiento contrapuntístico les confieren aires nuevos.»

Per tant, no és descartable que els textos de les ensalades proporcionessin un material conegut sobre el qual es pogués cantar improvisant amb certa facilitat. Al cap i a la fi, el material d'aquests cançoners està a mig camí entre l'escriptura i l'oralitat. Com afirma Frenk (1995: 161): «Buena parte de la poesía de los siglos XVI y XVII (...) era una poesía oralizada, o sea, escrita y luego, a menudo, memorizada y difundida mediante la recitación o el canto.»

I és possible que així les interpretessin les monges de Vic. Tenim un interessant testimoni coetani sobre pràctiques corèutico-musicals nadalenques dins d'aquesta mateixa comunitat: el de la germana Catalina de San José, Lanuza Vela (ca. 1600? - 1642), qui durant el Nadal, a més d'escriure versos, els cantava i ballava:

En la Pasqua de Navidad quería se hiziessen fiestas al divino Niño, y su reverencia hazíale versos y los cantava, que tenía buena voz, quando estava su magestad descubierto en la Iglesia,

SCRIPTA, Revista internacional de literatura i cultura medieval i moderna, núm. 7 / juny 2016 / pp. 187 - 219 ISSN: $2340-4841 \cdot$ doi:10.7203/SCRIPTA.7.8476 
se ponía a danzar en el coro, como otro David delante la arca del Viejo Testamento, y no contenta con hazerlo, su reverencia nos mandava a algunas que dançasemos también con el mesmo coro (...). ${ }^{16}$

De fet, la dansa era una activitat que la religiosa apreciava molt en les recreacions, i fins i tot l'usava amb finalitat psicoterapèutica per ajudar a altres germanes:

Sentía mucho faltazen las religiosas en recreación, y a una, porque era de su natural poco amiga de hablar, pensando nuestra madre Catalina estava triste, le mandó que todos los días en recreación baylace, y esto duró mucho tiempo. ${ }^{17}$

Qui sap si entre aquests moments d'esbarjo nadalenc, amb cants i balls impulsats per la germana Catalina de San José, hi hauria ensalades. Aquesta religiosa fou una de les primeres del convent procedents de Saragossa, i pertanyia a una de les famílies més importants d'Aragó (Gras 2013b). Com a membre de l'alta noblesa aragonesa, segurament tindria una sòlida formació no només musical, sinó també corèutica.

Aquesta presència de dansa no era un cas aillat en la vida carmelitana reformada. ${ }^{18}$ En el cançoner del convent de Barcelona podem trobar algunes peces per a ser ballades (Gras 2013a: 319; Zaragoza, en premsa). ${ }^{19} \mathrm{I}$, de fet, en el segon cançoner de Vic trobem un bonic exemple de com les monges festejarien el Nadal amb càntics i balls. Es tracta d'un romanç anònim (núm. 75) en què s'enumeren, amb to jocós, les «ofrenes musicals» que cada monja farà a la Verge pel naixement del seu Fill:

Lisarda, la supriora

que tiene voz de serena [sic: sirena]

os cantará Reyna mia

con su instrumento una letra.

Tambien os quiere cantar

16 ACDV, Breve relación..., pp. 262-263 (Gras 2013a: 319; 2013b).

17 ACVD, Breve relación..., pp. 263 (Gras 2013a: 319; 2013b).

18 I encara ho és en les recreacions, tal com ens van informar les monges de l'actual convent de Santa Teresa de Vic.

19 Mercè Gras (2013a: 319) ofereix un altre exemple del convent de les Descalces de Barcelona: en la crònica Luz de verdad del convent es narra una de les visites de l'arxiduquesa Elisabet Cristina de Brunswick, on es descriu la dansa monacal que practicaven les monges:

Dixeronle las religiosas que aunque estavan con tanta clausura y retiro también baylaban en su tiempo. Y, deseando su majestad verlas baylar, les dixo que baylaren. Y empezaron el bayle diziendo la canción, que empieza assí: «Oy es nuestro die, celebrémosle con mucha alegría, a Dios amaré». Su majestad, medio corriendo, se metió en el bayle y bayló con las madres asta que fue acabada la canción y bayle. Y su majestad le puse por nombre el «Bayle santo». 


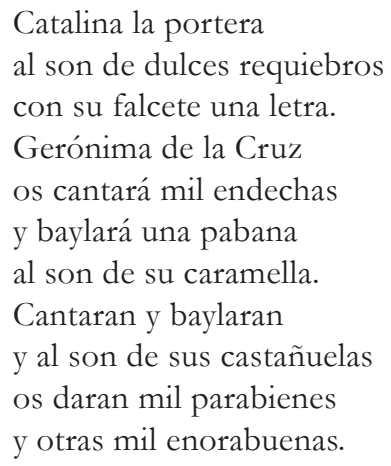

Aquest text descriu una celebració del Nadal dins de la comunitat on cada monja executaria el que millor sap fer: cantar, tocar instruments i/o ballar. Malauradament no sabem a quines monges es refereixen els noms apuntats: ${ }^{20}$ comparats els noms amb la documentació de l'ACDV resulta clar que no es tracta de monges del convent de Santa Teresa de Vic, la qual cosa indica que part d'aquest cançoner o bé es va escriure en un altre convent o bé es copià prenent com a model una obra forània, com veurem amb més deteniment. En qualsevol cas, és testimoni d'unes pràctiques lúdico-festives vinculades amb el Nadal on les monges participarien activament cantant, ballant $\mathrm{i}$ tocant instruments $\mathrm{i}$ on podrien cabre perfectament les ensalades del present volum.

\subsection{Altres obres d'aquest cançoner}

La resta del cançoner presenta un caire diferent, amb predomini d'obres posteriors, de finals del XVI i principis del XVII. Pel que fa al primer bloc, a banda dels casos que ja s'han comentat en referència a les ensalades, resulta interessant la presència de les follies amb text en català (núm. 8), que constaten la vinculació del manuscrit amb les terres de parla catalana; i la peça Toma, vivo te lo do (núm. 13), adaptació a lo divino d'un conegut joc de societat documentat ja a principis del segle XVI (Frenk 2013; Pedrosa 2013). Es tracta d'un joc de penyores que consistia en anar passant, d'un a altre d'un grup, una espelma o un llumí encès que cadascú havia de bufar fins que s’apagava. En aquest cas, el que es passaria «vivo» i sense apagar-se és l'hòstia, el pa com a cos de Crist.

20 Només he trobat la referència a una Gerónima de la Cruz que podria ser la del poema: Gerónima de la Cruz, Grasa Castillo, del convent de San José de Saragossa, que va morir el 4 d'octubre de 1646 (Lanuza 1659: 421). Lanuza la descriu d'una manera que no sembla coincidir amb el carácter distès que li atribueix el poema:

Geronima de la Cruz, Religiosa de velo blanco, hija de Sebastian de Grassa, y Maria Castillo, personas honaras, trabajó mucho en este Convento en servicio de la Comunidad. Fue muy mortificada; y tomava tan frequentes, y desapiadadas diciplinas, que se desangrava en las mas dellas. Tuvo grande amor al silencio, virtud tan importante en la vida espiritual, que sin el se pierde en breve rato, quanto se adquiere en la oracion en mucho tiempo (ibid.: 419). 
Aurèlia Pessarrodona. Ensalades en clausura: Una primera aproximació als cançoners del convent de les carmelites descalces de Santa Teresa de Vic

Encara que aquest text no faci referència directa a una activitat lúdica, la seva presència en el cançoner seria testimoni dels moments de distensió de la vida conventual, que es duien a terme durant les recreacions. El fet que el text repeteixi la tornada «Para do, para do / Por el alma sin pecado / que de aqueste pan comió» suggereix que el text seria cantat. Tal com observa Verònica Zaragoza en referència al Cançoner poètic del Convent de Carmelites Descalces de Barcelona (en premsa), en aquests repertoris abunden certs elements repetitius, propis del diàleg, que invoquen el seu caràcter oral i suggereixen que les peces van ser concebudes per tal de ser cantades col lectivament. És més, segons Rosalva Loreto (2000: 77), qui ha estudiat el paper del cant en convents femenins novohispans dels segles XVII i XVIII dins d'altres pràctiques comunitàries com la lectura i l'escriptura, l'adopció d'aquestes fórmules dins de la vida conventual servien «para determinar una identidad grupal donde la repetición de los mismos gestos y prácticas incorporaba en cada religiosa una conciencia de pertenencia al conjunto monástico, lo cual le proporcionaba una referencia esencial que daba sentido al mundo y a su existencia». Així, doncs, en aquest context de distensió i oci comunitari, el cant tindria una important funció de cohesió grupal. ${ }^{21}$

Malgrat això, al contrari del que veurem al Ms. 2, aquest cançoner no es caracteritza per ser testimoni de pràctiques directament vinculades amb esdeveniments concrets de la quotidiana del convent de Santa Teresa de Vic ni sembla un recull de l'activitat literària de les pròpies monges. De fet, moltes de la resta de peces són còpies de poemes de caire religiós d'escriptors espirituals de referència en aquella època, com Juan López de Úbeda (segona meitat del XVI), Arcángel de Alarcón (15361620), Luis Bertran (1526-1581), Hipòlita de Jesús Rocabertí (1551-1624), José de Valdivielso (1565-1638) o fins i tot Lope de Vega (1536-1620). Es mantenen les temàtiques, amb abundant presència de poemes dedicats al Nadal i al Santíssim Sacrament; i s'hi afegeix alguna obra sobre sants, com les cobles a Santa Caterina Màrtir en català (núm. 45). Pel que fa als gèneres, trobem des de poemes elevats escrits en sonets i lires, fins a altres de caire deliberadament popularitzant, en vilancets, romanços, cobles i seguidilles. Les últimes obres del cançoner segueixen aquestes mateixes línies, però apareixen escrites amb cal ligrafies diferents que no s'han pogut relacionar amb cap de les monges del convent de Santa Teresa de Vic. Tanca el volum un Ejercicio espiritual del Padre Fray Francisco del Santo Sacramento, l'única obra de caire assagístic del recull.

Pel que fa a la música, s'han trobat referències d'íncipits d'algunes d'aquestes obres amb d'altres de musicals, però encara caldria un estudi amb major profunditat per determinar si es tracta de les mateixes peces. Per exemple, consta que entre els vilancets de Joan Pau Pujol (1570-1626) n'hi havia un amb l'íncipit «En aquel altar de gloria» (núm. 47) (Lambea 1898: 80); o en el Cançoner de la Reial Acadèmia Espanyola RM 6212, del primer quart del segle XVII, s'hi troba una obra que coincideix amb el text del núm. 43 (Aguilar Serrano 2013: II, p. 48, nº 61). Es tractaria, doncs, d'un repertori musical temporalment més proper a la confecció del cançoner que no pas les ensalades.

21 I sembla que encara sigui així, tal com vam poder comprovar una visita al convent de Santa Teresa de Vic, on les monges, molt amablement, ens van interpretar cançons del seu repertori habitual, sobretot nadalenc, acompanyades de la guitarra i instruments de percussió.

SCRIPTA, Revista internacional de literatura i cultura medieval i moderna, núm. 7 / juny 2016 / pp. 187 - 219 ISSN: $2340-4841 \cdot$ doi:10.7203/SCRIPTA.7.8476 
Com a mostra de l'impacte que va tenir aquest repertori a l'època i del poder de la seva música, resulta interessant la següent anècdota sobre el romanç $A$ la regalada Esposa de José de Valdivielso (núm. 53). En la relació de la vida de la religiosa concepcionista María de Jesús de Ágreda (16021665), inclosa en el pròleg de la seva obra Mystica Ciudad de Dios (1709: I, p. cxxi), s'explica amb profusió de detalls el rapte espiritual que va viure la mística a l'escoltar com les seves companyes cantaven, precisament, el romanç de Valdivielso:

\begin{abstract}
Un día de San Lorenço, en que avia una Religiosa profesando, estando con las demás en la recreación, que según el estilo de la descalçez se de a la comunidad en semejantes días, y ocurrencias, para regozijar la fiesta cantaron algunas de ellas un devoto Romance, que comiença $A$ la regalada Esposa y elevándose con la musica, y la letra el espíritu de la Sierva de Dios, se quedó, como otras vezes arrobada. Estaban en un descubierto, que en la estrechez de aquella pobre casa les servía para estar recreaciones de huerta; y era ya casi de noche. En esta disposición a vista de todas las Religiosas, que atendían à la maravilla del rapto, como rompiéndose el Cielo, baxo un grande resplandor a modo de globo de luz, de extrema claridad, y belleza, que permaneció grande rato en esta forma. Vieronlo todas; ninguna dexò de admirarlo como celestial prodigio, y algunas refirieron el interior consuelo, que avian recibido con su vista.
\end{abstract}

Es tracta d'un excel lent exemple de l'estret vincle entre música i espiritualitat en el Barroc, amb un fort component espectacular molt sensorial i corporal (McClary 2012: cap. 5).

\title{
2. E1 Ms. 2: 1a pràctica literària conventual
}

Físicament, el Ms. 2 és similar al primer. Medeix 135 x 110 mm, té 1 f. en blanc s.n. +177 f. numerats +2 s.n. [índex] +1 f. en blanc. Està enquadernat en pergamí en mal estat i en el full enganxat a la coberta de pergamí hi ha una composició: Romance de gracia recién entrada en la religión. En el f. [1r] també hi apareix una composició que no sembla formar part del recull.

És un cançoner deliberadament sense títol, tal com s’indica al seu inici: «Este libro va sin nombre / y no es justo que le tenga / porque vive sin su dueño / en religion muy estrecha» (núm. 1). Malgrat el caire heterogeni del recull, els textos semblen seguir certs criteris d'agrupament de temàtica i de gènere, amb sèries de poemes sobre el mateix tema o en forma de romanços o sonets. Si bé els temes són força similars al Ms. 1, la diferència principal és que aquest, en lloc de recollir textos forans, reflecteix la creació literària — i potser també musical— dins de la vida conventual carmelitana. ${ }^{22} \mathrm{El}$ romanç de Nadal comentat anteriorment (núm. 75) n'és un exemple perfecte, com també ho són els nombrosos textos per a les preses del vel (per exemple, els núms. 7-12), un subgènere de poesia conventual perpetuat en el Carmel i freqüent en les autores religioses de l’època (Baranda 2011 i

22 S’hi inclou també algun text forà però de caire especialment carmelità, com el poema de la pròpia Santa Teresa del núm. 70. 
Aurèlia Pessarrodona. Ensalades en clausura: Una primera aproximació als cançoners del convent de les carmelites descalces de Santa Teresa de Vic

2013; Zaragoza, en premsa); ${ }^{23}$ o altres poemes que mostren el jo de la monja escriptora, bé en cartes en tercets al pare espiritual (núm. 45), bé en exposicions d'episodis autobiogràfics. Aquest seria el cas de la Canción al milagro de mi cura (núm. 41) on una monja anònima explica la miraculosa curació que va experimentar durant una dura malaltia.

Dins d'aquests diversos aspectes de la vida conventual resulten interessants les Seguidillas para la labor (núm. 29) com a mostra de cançó relacionada amb la dansa el ritme de la qual ajudaria a realitzar tasques de costura, potser de manera grupal durant les recreacions. Per tant, enllaçaria amb la funció cohesionadora i identitària de la música —inclosa la seva gestualitat— que hem vist al parlar del joc Toma, vivo te lo do.

Així, doncs, estaríem davant d'un recull d'obres creades per les pròpies monges, com també ocorre amb altres cançoners carmelitans com els de Valladolid, Medina del Campo, Úbeda i Barcelona. Però, com també s'ha apuntat, no tot el cançoner fa referència a les monges de Santa Teresa de Vic. A grans trets, trobem tres grans grups d'obres corresponents a diverses circumstàncies i etapes d'escriptura. El primer bloc correspon a les obres anotades a l'índex (núms. 1-50, és a dir, gairebé la meitat del cançoner), amb la mateixa cal ligrafia, desconeguda. El segon bloc (núms. 51-78) són obres afegides per altres mans, també desconegudes i segurament no pertanyents a Vic. En canvi, a partir del núm. 79 trobem cal ligrafies identificables amb monges del convent de Santa Teresa de Vic, tal com s'ha corroborat a través de llur coteig amb la Breve relación... Així, doncs, les dues primeres parts — fins el núm. 78 - serien d'origen forà, possiblement copiades en algun altre convent; i la resta es va anar completant a Vic, ja a la segona meitat del XVII.

La procedència més lògica seria el convent de Santa Teresa de Saragossa, d'on van arribar les primeres monges. A més, presenta una marca d'aigua (Fig. 5) que, segons Valls, podria ser de procedència catalana, ${ }^{24}$ però també es troba a l'Aragó en dates properes al manuscrit, sobretot en llibres de justícia de Daroca dels anys $1620 .^{25}$

23 Vegi’s també l'article de la mateixa Zaragoza dins d'aquest número de Scripta.

24 Diu Valls sobre les filigranes del tipus «cruz latina dentro boja o escudo»:

Con gran abundancia y sobre papel de calidad, por lo general mediana, nos encontramos con esta filigrana que dentro de la simplificación de su dibujo abuna con variedades dignas de hacer constar. Las primeras las hallamos en 1506, y terminan con el siglo XVIII. La misma variación y proliferación con que se encuentra esta filigrana, hace pensar en su procedencia catalana, tanto por la construcción del papel, fibras con gran cantidad de lino y pequeñas proporciones de cáñamo, etc. (Valls 1970: I, p. 387).

25 Vegi’s Filigranas en la provincia de Zaragoza núms. DPZ-0436, DPZ-0501, DPZ-0273, DPZ-0274. Consultable online: $<$ http:/ / fil.dpz.es $>$ [consulta: juny 2016]

SCRIPTA, Revista internacional de literatura i cultura medieval i moderna, núm. 7 / juny 2016 / pp. 187 - 219 ISSN: $2340-4841 \cdot$ doi:10.7203/SCRIPTA.7.8476 


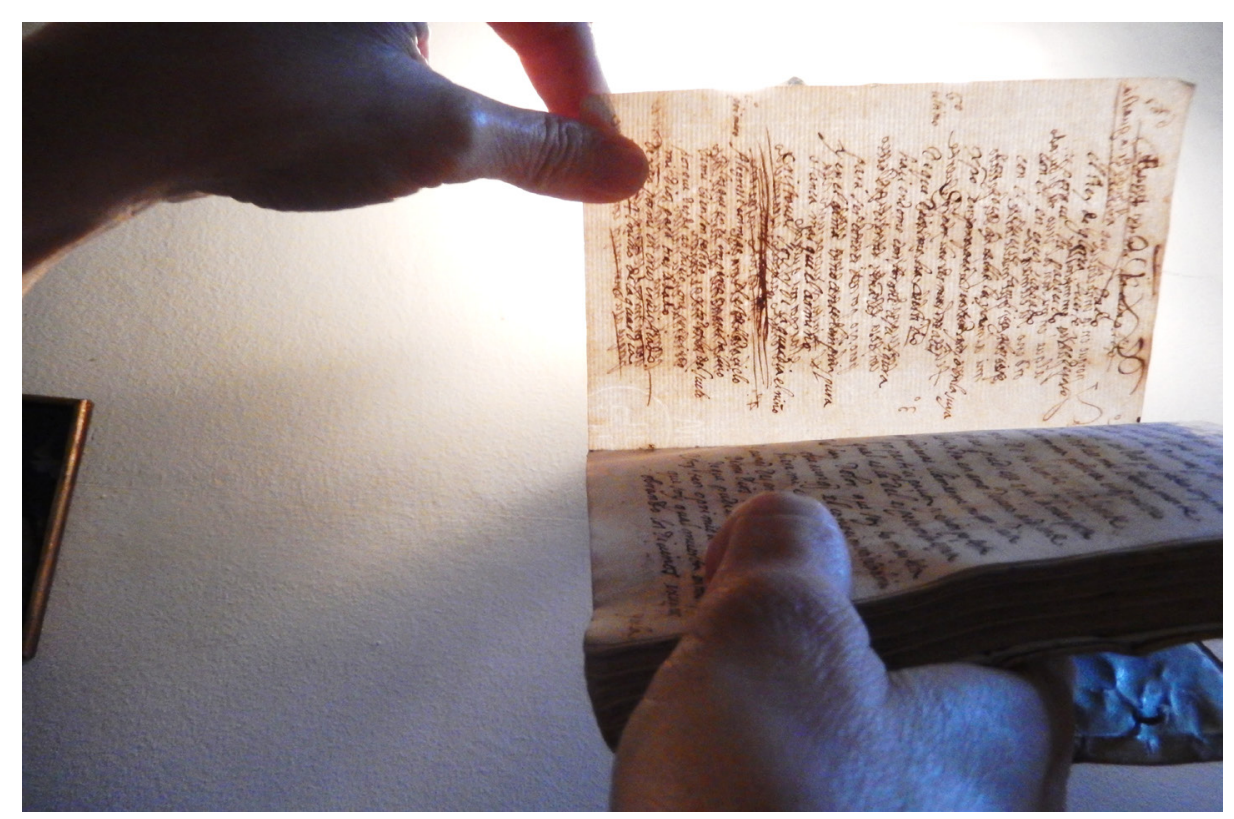

Figura 5: fragment f. 62v del Ms. 2 del convent de Santa Teresa de Vic amb detall de la marca d'aigua

El vincle amb Saragossa s'explicita en el núm. 21, un romanç «que se cantó en su fiesta el año 1626 en su casa Çarag'»", que sitúa l'obra a l'any 1626 relacionada amb algun dels dos convents de carmelites descalces d'aquesta ciutat. Però sobta trobar referències a l'altre convent carmelità de la ciutat, San José. Una apareix al núm. 9, el Villancico al habito de dona Mariana de Torrella, dama noble que canvià el nom pel de Ana María de Jesús i arribà a priora del convent de San José (Lanuza 1638: índex; 1659: 395-414). Una altra es dóna al núm. 48, el Soneto a la muerte de la madre Paula de San Alberto, dedicat a una important monja del convent de San José de Saragossa, natural de Tarazona i filla de Francisco de Casanate (Lanuza 1638: 512-517; 1659: 252-262). La biografia que aporta Miguel Batista Lanuza inclou la següent informació:

\footnotetext{
Desde muy niña se descubrió en Paula agudo entendimiento, y virtuosas inclinaciones; y en particular la de ser Religiosa, con pedirlo a sus Padres, y hablar muchas vezes dello. Sobre este fundamento la enseñaron desde aquella edad, a leer y cantar; porque pensaven ponerla (quando fuesse tiempo) en el Convento de la Concepción de Tarazona; donde, a la sazon, vivian sus Padres. Pero como entraron dos hermanos suyos en la Religión de los Descalzos Carmelitas, tuvo noticia Paula, de que avia Monjas de la misma Orden; y luego se le fueron los ojos tres la fama de la santidad destas Religiosas y el deseo de ser una dellas (Lanuza 1638: 512-513, subratllat meu).
}

Aquesta citació és un excel lent exemple de l’alta educació — també musical— que, com s’apuntava més amunt, rebien les nenes de famílies d'alt estatus, justificada en aquest cas per la vocació primerenca de la Paula. 
Aurèlia Pessarrodona. Ensalades en clausura: Una primera aproximació als cançoners del convent de les carmelites descalces de Santa Teresa de Vic

No era estranya la circulació d'obres entre convents. Com diu Llergo (2012: 137) «la circulación de las letras de los villancicos entre las distintas instituciones religiosas españolas era una práctica común en la época». De totes formes, aquest cançoner suggereix certes relacions entre els dos convents carmelitans i el de Vic que encara estan pendents d'estudi i que requeririen un coteig amb els arxius dels convents carmelitans de Saragossa que en aquesta ocasió no s'ha pogut realitzar.

Com s'ha apuntat, a partir del núm. 64 i fins el 73 se succeeixen diversos canvis de lletra, totes desconegudes. Podrien tenir origen a Saragossa, però algun text semblaria tenir certa relació amb la comunitat vigatana. És el cas del núm. 76, un romanç on s'explica, amb to desenfadat i divertit, la confessió d'un petit furt per part d'una germana anomenada «Ysabel de los Ángeles». Al convent de Santa Teresa hi consta una religiosa anomenada Isabel dels Àngels, Mora, viuda Pujalt (16321667), que prengué els vels el 28 de març de 1638 i professà el 8 d'abril de 1639 (ref.), però no hi ha cap dada que confirmi que el romanç faci referència a aquesta monja. Per altra banda, el núm. 77 es tracta d'un romanç per a l'entrada en el convent de les carmelites descalces «de la hermana María de Jesus de la ciudad de Barcelonar: al convent de Vic no consta cap religiosa amb aquest nom provinent de Barcelona, per tant potser podria ser una referència a Maria de Jesús, Ramon Ayllà, que professà el 1648 al convent de la Puríssima Concepció de Barcelona i a qui ja s'ha anomenat anteriorment pel seu talent musical.

A partir del núm. 79 les mans apareixen relacionades directament amb el Convent de Santa Teresa de Vic. El Romance de un alma que trajo Dios del siglo a la religión de carmelitas (núm. 7) coincideix amb una cal ligrafia molt habitual en la documentació de l'ACDV de mitjans del XVII, però l'autora de la qual no s'ha pogut identificar. La lletra dels poemes següents (núms. 80-83) coincideix amb la d'Esperança de Jesús, Metge i Forns (1624-1681), de la qual només sabem que era natural de Vic, filla dels també vigatans Jaume Metge i Maria Àngela Forns, que prengué els vels el 21 de desembre de 1640 i professà un any després. ${ }^{26}$ Els dos vilancets que segueixen (núms. 84-85) foren escrits per Maria de la Concepció, Palau (1629-1703), i estan dedicats a la professió d’una altra religiosa, Teresa de Sant Josep, Bojons Sala (1652-1713). Com que sabem que aquesta monja rebé la vestició el 30 d'agost de 1670 i la professió el 5 de setembre de $1671,{ }^{27}$ els poemes són datables en aquests anys. A continuació trobem diversos poemes a Santa Teresa, uns escrits per la mateixa Teresa de Sant Josep (núms. 86 i 89) i els altres per Francesca de la Verge, Vila Bauló (núms. 87 i 88) (16481716), qui rebé la vestició el 14 d'agost de 1664 i féu la professió el 8 de setembre de 1675. Per tant, els poemes d'aquest últim bloc poden datar-se a la segona meitat del XVII, i els últims fins i tot podrien ser d'inicis del segle següent.

26 ACDV, Breve relación..., p. 54. No es dóna cap més dada de la seva biografia.

27 ACDV, Breve relación..., p. 131.

SCRIPTA, Revista internacional de literatura i cultura medieval i moderna, núm. 7 / juny 2016 / pp. 187 - 219 ISSN: $2340-4841 \cdot$ doi:10.7203/SCRIPTA.7.8476 
Aurèlia Pessarrodona. Ensalades en clausura: Una primera aproximació als cançoners del convent de les carmelites descalces de Santa Teresa de Vic

Si bé les identificacions d'aquestes mans són a vegades força dubtoses, ${ }^{28}$ no ho és en absolut en el cas de Maria de la Concepció, i tampoc no ho sembla en el de Teresa de Sant Josep. Ambdues es compten entre les monges més carismàtiques de la història del convent de Vic. Tal com documenta Mercè Gras (2013b), la primera havia nascut a Perpinyà l'any 1629, era filla de misser Lluís Palau, jurista de Perpinyà, i de Maria, després casada amb el capità Francisco de Sotomayor. Va ingressar al convent de Santa Teresa de Vic el 17 de novembre de 1644, en plena Guerra dels Segadors; i un any després, el 10 de desembre de 1645, feia la seva professió solemne. Religiosa de gran personalitat i força ascendència a la comunitat, fou priora des de 1697 fins al 7 de febrer de 1701, quan la succeí Maria Alberta de Sant Domènec. Però anteriorment havia sigut l'amanuense i cronista de la comunitat, amb la redacció d'obres importants dins de la història del convent com una biografia de la religiosa Maria de les Llagues (Maria Osona Mongraula, 1591-1650), cofundadora i primera religiosa professa a la nova casa; ${ }^{29}$ una crònica de la fundació del convent; ${ }^{30}$ i unes notes autobiogràfiques on explica les seves experiències, escrites per ordre del seu confessor. ${ }^{31}$ També és molt possible que redactés les notes necrològiques o elogis de difuntes de les religioses de la seva comunitat.

Pel que fa a Teresa de Sant Josep, era natural de Vic, filla de Francesc Bojons i d'Estàsia Sala, ciutadans honrats d'aquesta ciutat. Va ser clavària de la comunitat el 1701 i el 1704. Segons la nota necrològica, «fue religiosa muy observante de nuestra santes leyes y tenia un santo zelo que nunca se faltase al exacto complimiento de elles. Era religiosa de linda capacidad y de mucha prudència y modestia, muy exercitada en la oración y trato interior con Dios». ${ }^{32}$ La faceta més destacada d'aquesta monja relacionada amb l'escriptura conventual és la correspondència de temàtica espiritual i experiència religiosa que va mantenir, entre aproximadament 1671 i 1713, amb Josep de Sant Benet o «de les llànties» (1654-1728), frare montserratí, escriptor d'ascètica i mística. Malauradament, d'aquesta correspondència només es conserven les cartes del monjo a la religiosa (Argerich 1746: cartes XIII i XIV; Beltran 1990: 186, 206, 208, 223, 232, 275, 291).

Així, doncs, la troballa d'aquests poemes atribuibles a Maria de la Concepció i Teresa de Sant Josep venen a completar el perfil literari d'ambdues, afegint-hi la faceta lírica i possiblement també la musical, ja que la factura de les obres suggereix que eren cantades.

28 Els documents de les professions, usats per al coteig de les mans, normalment presenta les lletres de quan les religioses eren molt joves.

29 Relación de la vida de María de las Llagas Osona (1650). Es troba dins de Breve relación..., pp. 8-14.

30 ACDV, Primer origen de la fundación de aqueste convento de carmelitas Descalzas de la ciudad de Vique y fundadoras del en lo espiritual y temporal, intitulado de Jesús, María, Joseph y Teresa, sense signatura.

31 Misericordias y gracias que dispensó Dios con una religiosa del convento de Santa Theresa de Vique, cuyo nombre fue la venerable madre María de la Concepción, que murió a los 19 de abril del año 1703, copiat dins de la Breve relación..., pp. 72-83

32 ACDV, Breve relación..., p. 132.

SCRIPTA, Revista internacional de literatura i cultura medieval i moderna, núm. 7 / juny 2016 / pp. 187 - 219 ISSN: $2340-4841 \cdot$ doi:10.7203/SCRIPTA.7.8476 
Aurèlia Pessarrodona. Ensalades en clausura: Una primera aproximació als cançoners del convent de les carmelites descalces de Santa Teresa de Vic

\section{Conclusions}

Amb aquest treball s'ha fet una primera aproximació als dos cançoners custodiats a l'ACDV, amb la intenció de valorar llur importància, situar-los dins llur contextos i plantejar una sèrie de reflexions i suggeriments de cara a incentivar properes investigacions.

Aquesta primera ullada mostra dues pràctiques textuals diferents però en general molt relacionades amb la praxi performativa. Si bé els textos eren susceptibles de ser només llegits en la intimitat del silenci, moltes de les obres suggereixen interpretacions que inclourien música, text, teatre i dansa, per part de monges amb un alt nivell cultural que també podien tenir una important faceta creativa. En aquest context les ensalades de Fletxa, rares en aquests cançoners, adquireixen sentit. El silenci de la clausura no estava renyit amb aquests moments d'esbarjo que creaven vincles identitaris dins de la comunitat. 
Aurèlia Pessarrodona. Ensalades en clausura: Una primera aproximació als cançoners del convent de les carmelites descalces de Santa Teresa de Vic

\section{Bibliografia}

Ágreda, María de Jesús de (1709) Mystica Ciudad de Dios, milagro de su omnipotencia, y abismo de la gracia divina y vida de la Virgen Madre de Dios (...), Amberes: Henrico y Cornelio Verdussen.

Aguilar Serrano, P. (2013) Aspectos comunicativos del cancionero inédito del siglo XVII RAE RM 6212: edición crítica, tesis doctoral inèdita, Madrid: Facultad de Ciencias de la Información, Departamento de Periodismo III (consultable online: < http://eprints.ucm.es/22433/>).

Alberch Vila, P. (1561) Odarum (Quas vulgo madrigales appellamus) dinersi linguis decantatarum harmònica, noua \& excellenti modulatione compositarum, Liber primus: altus, Barcinone: in aedibus Iacobi Cortey.

—_. (1983) ElBon Jorn, estudi i transcripció de Josep Maria Gregori, Barcelona: Institut Universitari de Documentació i Investigació Musicològica Ricart i Matas.

Alín, J. M. (1998) «Francisco Salinas y la canción popular del siglo XVI», dins Piñero Ramírez, P. (ed.) Lírica popular, lírica tradicional. Lecciones en homenaje a Don Emilio García Gómez, Sevilla: Universidad de Sevilla, Fundación Machado, pp. 137-157.

Álvarez Pelliter, A. M. (1983) «Cancionero del Carmelo de Medina del Campo », dins Actas del Congreso Internacional Teresiano (Salamanca, 4-7 octubre 1982), vol. II, pp. 526-543.

Anastasio de Santa Teresa (1739) Reforma de los Descalzos de Nuestra Señora del Carmen de la Primitiva Observancia, VII, Madrid: Imprenta Real; Miguel Francisco Rodríguez.

Arcángel de Alarcón (1594) Vergel de plantas divinas en varios metros espirituales, Barcelona: Emprenta de Jayme Cendrat.

Argerich, B. (1746) Vida interior y cartas que escribió a diferentes personas fray Joseph de San Benito, religioso lego en el monasterio de nuestra Señora de Montserrat [...], Madrid.

Baranda, N. (2011) «Cantos al sacro epitalamio o sea pliegos poéticos para las tomas de velo: deslindes preliminares», Bulletin Hispanique, 113-1, pp. 269-296.

- (2013) «Producción y consumo poéticos en los conventos femeninos», Bulletin Hispanique, 1151, pp. 165-184.

Beltran, G. (1990) Carmelitas Descalzas de Cataluña y Baleares, Roma: Teresianum.

Castro, Guillén de (1997) Obras completas, ed. i pròleg de Joan Oleza, Madrid: Fundación José Antonio de Castro.

Calahorra, P. (1992) «Los fondos musicales en el siglo XVI de la Catedral de Tarazona. I. Inventarios», Nassarre: Revista Aragonesa de Musicología, 8-2, pp. 9-56.

Díaz-Mas, P. (1985) «Sobre la fortuna del romance Mira Nero de Tarpeya», dins Melena J. L. (ed.) Symbolae Ludovico Mitxelena septuagenario oblatae, Victòria: Instituto de Ciencias de la Antigüedad, Universidad del País Vasco, vol. I, pp. 795-798.

Escrivà Llorca, F. (2007) «Aproximació històrica a la música de Gandia al segle XVI. Institucions musicals i fonts relacionades», treball de màster inèdit, València: Universitat Politècnica de València.

SCRIPTA, Revista internacional de literatura i cultura medieval i moderna, núm. 7 / juny 2016 / pp. 187 - 219 
Aurèlia Pessarrodona. Ensalades en clausura: Una primera aproximació als cançoners del convent de les carmelites descalces de Santa Teresa de Vic

. (2015) Eruditio, pietas et honor: Joan de Borja i la música del seu temps (1533-1606), València: Universitat Politècnica de València.

Fiorentino, G. (2009) Música española del Renacimiento entre tradición oraly transmisión escrita: el esquema de folía en procesos de composición e improvisación, tesi doctoral, Granada: Universitat.

Filigranas en la provincia de Zaragoza, recurs online: <http://fil.dpz.es> [consulta: juny 2016].

Fletxa [el Vell], Mateu, i altres (1581) Ensaladas de Flecha, Maestro de capilla que fue de las Serenissimas Infantas de Castilla, Recopiladas por F. Matheo Flecha su sobrino... con algunes suyas y de otros autores por el mismo corregidas y echas estampar, Praga: Jorge Negrino.

Frenk Alatorre, M. (1995) «El cancionero oral en el Siglo de Oro», dins Poesía popular hispànica. 44 estudios, Mèxic: Fondo de Cultura Económica, pp. 159-175.

. (2003) Nuevo corpus de la antigua lírica popular hispánica (siglos XV a XVII), México: Fondo de Cultura Económica.

- (2013) «Rimas para juegos infantiles en el antiguo cancionero popular», Ocnos, 9, pp. 7-20 (consultable en línia: <http://www.revista.uclm.es/index.php/ocnos/issue/view/125>).

García de la Concha, V., i Álvarez Pellitero, A. M. (1982) Libro de romances y coplas del Carmelo de Valladolid, Salamanca: Consejo General de Castilla y León, 2 vols.

Gómez Muntané, M. (estudi i edició crítica) (2008) Las ensaladas (Praga, 1581), València: Generalitat Valenciana.

González Marín,L. A. (1997) «Algunas consideracions sobre la música para conjuntos instrumentales del siglo XVII español», Anuario Musical, 52, pp. 101-141.

Gracián (1919) Notas para la historia de Sabiñan. Segunda parte, revisat per Francisco Tobajas Gallego per a l'edició en línia (2013): <https://issuu.com/sabinius/docs/2.1_n> [consulta: juny 2016].

Gras, M. (2013a) «L'escriptura en el Carmel descalç femení: la província de Sant Josep de la Muntanya (1588-1835)», Scripta. Revista Internacional de Literatura i Cultura Medieval i Moderna, 1, juny, pp. 302-332.

. (2013b) Diccionari biogräfic d'autors carmelites descalços de la provincia de Sant Josep, consultable en línia dins de Base de dades de Manuscrits Catalans d'Edat Moderna (=MCEM): <http://mcem.iec. cat> [consulta: juny 2016].

—_. (2015) «Música per a carmelites descalces», dins Toldrà, M. (ed.) Castell interior. Santa Teresa de Jesús $i$ els carmelites descalcos de Catalunya, blog consultable en línia: <https://castellinterior. wordpress.com/> [consulta: juny 2016].

Gregori, J. M. (1986-87) «La nissaga dels organistes Vila i les famílies Vila, Alberch, Ferran i Ferrament de la ciutat de Vic al s. XVI», Recerca Musicològica, 6-7, pp. 49-76.

. (1987) La música del Renaixement a la Catedral de Barcelona, 1450-1580, tesi doctoral [presentada a la] UAB l'any 1986, Bellaterra: Servei de Publicacions de la Universitat Autònoma de Barcelona. 
Aurèlia Pessarrodona. Ensalades en clausura: Una primera aproximació als cançoners del convent de les carmelites descalces de Santa Teresa de Vic

. (2004) «Aspectes de la relació musical entre Catalunya i València durant el Renaixement», dins III Jornadas Nacionales de Música, Estética y Patrimonio, Xàtiva: Ajuntament, pp. 153-167.

Hanna, D. (2015) «Pour la fête de notre séraphique mère sainte Thérèse: A Teresian Celebration in Verse, and a Concise View of French Carmelite Poetry», Scripta, núm. 6, desembre 2015, pp. 166-175.

Kruger-Hickman, K. (1984) «La ensalada. Hacia la tipología de un género híbrido», monografia inèdita, La Jolla.

Lambea, M. (1989) «La obra musical de Joan Pau Pujol sobre textos en castellano», Anuario Musical, 44, pp. 61-83.

(1997) «Una ensalada anónima del s. XVII de los Romances y letras de a tres voces (Biblioteca Nacional de Madrid)», Anuario Musical, 51, pp. 71-110.

- (2012) Nuevo incipit de la poesía española musicada, Alacant: Biblioteca Virtual Miguel de Cervantes.

Lanuza, Miguel Baptista de (1638) Vida de la bendita Isabel de Santo Domingo, Madrid: Imprenta del Reino.

- (1659) Fundación y excelencias, del Convento de S. Joseph de Carmelitas descalzas de Caragoca. Vidas y elogios de treynta Religiosas que han vivido y muerto en el, con fama de Santidad, Saragossa: herederos de Pedro Lanaja y Lamarca.

Ledesma, Alonso de (1602) Conceptos espirituales de Alonso de Ledesma, natural de Segovia. Dirigidos a nuestra Señora de la Fuencisla, Madrid: Imprenta Real.

Llergo, E. (2012) «Representación y representabilidad en los villancicos paralitúrgicos de las Descalzas Reales», eHumanista, 21, pp. 132-161.

López-Calo, J. (1963) La mísica en la catedral de Granada en el siglo XV I, Granada: Fundación Rodríguez-Acosta, 2 vols.

López de Úbeda, J. (1962) Cancionero general de la Doctrina cristiana, hecho por Juan López de Úbeda (1579, 1585, 1586), Madrid: Sociedad de Bibliófilos Españoles.

Loreto, R. (2000) «Leer, contar, cantar y escribir. Un acercamiento a las prácticas de la lectura conventual. Puebla de los Ángeles, México, siglos ХИІІ у ХИІІळ〉, Estudios de Historia Novohispana, 23, pp. 67-95.

McClary, S. (2012) Desire and Pleasure in Seventeenth Century Music, Berkeley: University of California Press.

Moll, J. (1970) «Los villancicos cantados en la Capilla Real a fines del siglo XVI y principios del siglo XVII», Anuario Musical, 25, pp. 81-96.

Morales Borrero, M. (1993) «El Convento de Carmelitas Descalzas de Úbeda y notia de sus manuscritos», Boletín del Instituto de Estudios Giennenses, 147, pp. 7-60.

Pedrosa, J. M. (2013) «"Toma, vivo te lo do": avatares y rescrituras viejas y modernas de un juego infantil», dins Cerrillo Torremocha, P. C., i Sánchez Ortiz, C. (eds.) Presencia del cancionero popular infantil en la lírica hispánica, Cuenca: Universidad de Castilla la Mancha, pp. 167-181.

SCRIPTA, Revista internacional de literatura i cultura medieval i moderna, núm. 7 / juny 2016 / pp. 187 - 219 
Aurèlia Pessarrodona. Ensalades en clausura: Una primera aproximació als cançoners del convent de les carmelites descalces de Santa Teresa de Vic

Querol, M. (ed.) (1987) Cancionero musical de Lope de Vega, Barcelona: Consejo Superior de Investigaciones Científicas.

Romancero general, en el que se contienen todos los romances que andan impresos en las nueue partes de Romanceros (1600), Madrid: Luis Sánchez, a costa de Miguel Martínez.

Romancero general, en el que se contienen todos los romances que andan impresos (1604), Madrid: Juan de la Cuesta.

Rubio de la Iglesia, F. (2014) «Las melodías populares en De Musica libri septem, de Francisco de Salinas: estudio comparado de algunos ejemplos», dins García Pérez, A., i Otaola González, P. (coords.) Francisco de Salinas. Música, teoría y matemática en el Renacimiento, Salamanca: Universidad, pp. 219-231.

Salinas, F. de (1577) De Musica libri septem, Salamanca: Mathias Gast.

Serrano, M. (1905) Apuntes para una biblioteca de escritoras españolas, Madrid: Tipografía de Archivos.

Serrano Plaja, A. (ed.) (1943) Hijo del alba. Villancicos, canciones, ensaladillas, coloquiospastoriles. Nochebuena, Buenos Aires: Imprenta López.

Tenorio, M. L. (1999) Los villancicos de Sor Juana, Mèxic: El Colegio de México.

Teresa de Jesús (1613) Modo de visitar los conventos, Madrid: Alonso Martín.

Valdivielso, José de (1680) Romancero espiritual, en gracia de los esclavos del Santíssimo Sacramento, para cantar cuando se muestra descubierto, Valencia: Juan Lorenço Cabrera.

(1880) Romancero espiritual, en gracia de los esclavos del Santísimo Sacramento, para cantar cuando se muestra descubierto, Madrid: Imprenta de Pérez Durrull.

Valls i Subirà, Oriol (1970) Elpapel y sus filigranas en Catalunya, Amsterdam: The Paper Publication Society, 2 vols.

Varey, J. E. (1979) Los titeres y otras diversiones populares de Madrid: 1758-1840. Estudio y documentos, Londres: Tamesis.

Villanueva, F. (2009) «Mateo Flecha el Viejo en la Catedral de Valencia: sus dos períodos de magisterio de capilla (1526-1531? y 1539-1541) y su entorno musical», Anuario Musical, 64, pp. 57-108.

Zaragoza, E. (2004) Història de la congregació benedictina claustral tarraconense i cesarangustana (1215 1815), [Barcelona]: Publicacions de l'Abadia de Montserrat.

- (en premsa) «"Cantadle al uso de corte un villancico galán”. Primera aproximación al Cancionero pético del convento de carmelitas descalzas de Barcelona (c. 1588-1805)», Relaciones. 
Aurèlia Pessarrodona. Ensalades en clausura: Una primera aproximació als cançoners del convent de les carmelites descalces de Santa Teresa de Vic

Apèndix I: taula del contingut del Cançoner Ms. 1 (ACDV)

\begin{tabular}{|c|c|c|c|c|c|c|}
\hline [Núm.] & Fols. & Rúbrica & Íncipit & Exxplicit & Autoria i/o referències. Altres observacions & mà \\
\hline & 2 ff. s.n. & $\begin{array}{l}\text { [index:] } \\
\text { Canciones del Nacimiento de } \\
\text { Christo } \\
\text { Ensaladas a lo divino } \\
\text { Del Santissimo sacramento } \\
\text { Canciones A Nuestra Senyora }\end{array}$ & & & & $1^{2} \mathrm{ma}$ \\
\hline 1 & $1 \mathrm{r}-1 \mathrm{v}$ & $\begin{array}{l}\text { Canción del nacimiento de } \\
\text { Christo }\end{array}$ & $\begin{array}{l}\text { Pues Dios al hombre } \\
\text { libró }\end{array}$ & No le miedo yo no no & & \\
\hline 2 & $1 \mathrm{v}-4 \mathrm{v}$ & $\begin{array}{l}\text { Ensalada para la noche de } \\
\text { Navidad }\end{array}$ & $\begin{array}{l}\text { Corret, corret, } \\
\text { pecadores }\end{array}$ & $\begin{array}{l}\text { Non morietur in } \\
\text { eternum }\end{array}$ & $\begin{array}{l}\text { Ensalada de Mateu Fletxa el Vell Fuego (Fletxa } \\
\text { 1581). }\end{array}$ & \\
\hline 3 & $4 \mathrm{v}-6 \mathrm{r}$ & $\begin{array}{l}\text { Colloquio entre Nuestra Señora } \\
\text { y los pecadores }\end{array}$ & $\begin{array}{l}\text { O Virgen en quien Dios } \\
\text { mora }\end{array}$ & $\begin{array}{l}\text { Que por nosotros } \\
\text { rogueys. }\end{array}$ & & \\
\hline 4 & $6 \mathrm{v}-9 \mathrm{r}$ & $\begin{array}{l}\text { Ensalada para la noche de } \\
\text { Navidad. Navegación. }\end{array}$ & $\begin{array}{l}\text { Bomba, bomba, agua } \\
\text { fuera }\end{array}$ & $\begin{array}{l}\text { Et pericula in falcis } \\
\text { fratribus. }\end{array}$ & $\begin{array}{l}\text { Ensalada de Mateu Fletxa el Vell La bomba } \\
\text { (Fletxa 1581). }\end{array}$ & \\
\hline 5 & $9 \mathrm{v}-10 \mathrm{r}$ & $\begin{array}{l}\text { Canción del nacimiento de } \\
\text { Christo }\end{array}$ & $\begin{array}{l}\text { Noche más clara quel } \\
\text { día }\end{array}$ & Parió la Virgen hermosa & $\begin{array}{l}\text { L'íncipit apareix copiat l'any } 1581 \text { en les } \\
\text { despeses del copista de la Capella Reial com a } \\
\text { vilancet a } 1 \text { i a } 8 \text { (Moll 1970: 91). També en el } \\
\text { Ms } 3902 \text { de la BNE (Frenk 2003: 728) }\end{array}$ & \\
\hline 6 & $10 \mathrm{r}-17 \mathrm{v}$ & Ensalada mui graciosa & Levanta Gil andaca & Secula seculorum Amén & Ensalada de Càrceres La Trulla (Fletxa 1581) & \\
\hline 7 & $18 \mathrm{r}-19 \mathrm{r}$ & Follies & Jesús en Bellem & Fonc crucificat & Text en català. & \\
\hline 8 & $19 \mathrm{r}-22 \mathrm{r}$ & $\begin{array}{l}\text { Ensalada para la noche de } \\
\text { Navidad }\end{array}$ & Bon jorn, bon jorn & Domini ibimus & $\begin{array}{l}\text { Ensalada de Pere Alberch Vila, Bon jom (Fletxa } \\
\text { 1581). }\end{array}$ & \\
\hline 9 & $22 \mathrm{r}-23 \mathrm{r}$ & $\begin{array}{l}\text { Canción del nacimiento de } \\
\text { Christo en lengua francesa }\end{array}$ & $\begin{array}{l}\text { Erray cat de byus } \\
\text { Ernauto }\end{array}$ & $\begin{array}{l}\text { Ben cosuda a la gran } \\
\text { garra }\end{array}$ & En occità. & \\
\hline 10 & $23 \mathrm{v}-25 \mathrm{v}$ & & Dinos quien es ese tal & Aleluya, aleluja & $\begin{array}{l}\text { Ensalada de Mateu Fletxa el Vell La negrina } \\
\text { (Fletxa 1581), però falten els primers versos. } \\
\text { Apareix a l'índex com a «Cumplido es ya mi } \\
\text { deseo» (el de l'ensalada de Fletxa és «Cumplido } \\
\text { es ya nuestro deseon). }\end{array}$ & \\
\hline 11 & $26 r-27 r$ & $\begin{array}{l}\text { Canción del santíssimo } \\
\text { Sacramento dicen Joan y } \\
\text { Andrés }\end{array}$ & Qué te paresse? Di Juan & $\begin{array}{l}\text { Es Dios } \\
\text { verdaderamente. }\end{array}$ & & \\
\hline
\end{tabular}

\begin{tabular}{|c|c|c|c|c|c|}
\hline 12 & $27 \mathrm{v}-30 \mathrm{r}$ & Ensalada & Una lucha arma Satán & $\begin{array}{l}\text { Será penado con gran } \\
\text { dolor }\end{array}$ & $\begin{array}{l}\text { Ensalada de Pere Alberch Vila La lucba (Fletxa } \\
\text { 1581). }\end{array}$ \\
\hline 13 & $30 \mathrm{r}-31 \mathrm{v}$ & $\begin{array}{l}\text { Canción del santíssimo } \\
\text { Sacramento }\end{array}$ & Toma bivo te lo do & $\begin{array}{l}\text { Que de queste pan } \\
\text { comió }\end{array}$ & $\begin{array}{l}\text { Versió a lo divino del joc «sopla (o toma), vivo te } \\
\text { lo do» (Frenk 2013; Pedrosa 2013). }\end{array}$ \\
\hline 14 & $32 \mathrm{r}-34 \mathrm{r}$ & $\begin{array}{l}\text { Ensalada para la noche de } \\
\text { Navidat. El Molino }\end{array}$ & Manso el molino amigo & Visitare no in pase & Ensalada ElMolino de Chacón (Fletxa 1581). \\
\hline 15 & $34 \mathrm{v}-36 \mathrm{r}$ & $\begin{array}{l}\text { Quartillas al santíssimo } \\
\text { Sacramento }\end{array}$ & Venit presto, pecadores & Hase Dios de sí manjar. & \\
\hline 16 & $36 \mathrm{r}-38 \mathrm{v}$ & $\begin{array}{l}\text { Ensalada del nacimiento de } \\
\text { Christo }\end{array}$ & En revenant dun molin & $\begin{array}{l}\text { Y el su baptista sant } \\
\text { Juan }\end{array}$ & $\begin{array}{l}\text { Ensalada Los cbistes de Mateu Fletxa el Vell } \\
\text { (Fletxa 1581) }\end{array}$ \\
\hline 17 & $39 \mathrm{r}-40 \mathrm{r}$ & Del santo Sacramento. Canción & Si miráis mis ojos & Dios Bibo estallí. & \\
\hline 18 & $40 \mathrm{v}-43 \mathrm{r}$ & Ensalada de Navidat. La feria & Feria franca, feria franca & $\begin{array}{l}\text { Venient et adorabunt } \\
\text { coramte domine. }\end{array}$ & $\begin{array}{l}\text { Ensalada La Feria de Mateu Fletxa el Jove } \\
\text { (Fletxa 1581). }\end{array}$ \\
\hline 19 & $43 \mathrm{v}-45 \mathrm{v}$ & $\begin{array}{l}\text { Canción del santíssimo } \\
\text { Sacramento, sobre y al tono de } \\
\text { Caminad Señora ec. Disen Sios } \\
\text { [sic, per «Dios»] y el Alma }\end{array}$ & Dios: Ven alma dichosa & Quiero yo gustar. & $\begin{array}{l}\text { Caminad señora va ser una cançó molt popular als } \\
\text { segles XV i XVI. Apareix al De Musica libri septem } \\
\text { de Francisco de Salinas (1577: 308; Rubio de la } \\
\text { Iglesia 2014: 230-231) }\end{array}$ \\
\hline 20 & $46 \mathrm{r}-48 \mathrm{v}$ & $\begin{array}{l}\text { Ensalada para Navidat. La } \\
\text { guerra }\end{array}$ & $\begin{array}{l}\text { Pues la guerra está en } \\
\text { las manos }\end{array}$ & Fides nostra & $\begin{array}{l}\text { Ensalada La guerra de Mateu Fletxa el Vell (Fletxa } \\
\text { 1581) }\end{array}$ \\
\hline 21 & $48 \mathrm{v}-49 \mathrm{r}$ & A Nuestra Señora & $\begin{array}{l}\text { Quando contemplo en } \\
\text { ti Virgen Maria }\end{array}$ & $\begin{array}{l}\text { De los que sin sesar } \\
\text { testán llamando }\end{array}$ & $\begin{array}{l}\text { Madrigal de Pere Alberch Vila recollit en Odarum } \\
\text { (1561). }\end{array}$ \\
\hline 22 & $49 \mathrm{v}-53 \mathrm{r}$ & Ensalada. Justas & Oid, oid los vivientes & $\begin{array}{l}\text { Buenas pasquas y buen } \\
\text { anyo }\end{array}$ & $\begin{array}{l}\text { Ensalada La justa de Mateu Fletxa el Vell (Fletxa } \\
\text { 1581). }\end{array}$ \\
\hline 23 & $53 \mathrm{v}-54 \mathrm{r}$ & $\begin{array}{l}\text { Romance del santíssimo } \\
\text { Sacramento }\end{array}$ & $\begin{array}{l}\text { A la hermosa y querida } \\
\text { alma }\end{array}$ & $\begin{array}{l}\text { Que amor con amor se } \\
\text { paga }\end{array}$ & \\
\hline 24 & $55 \mathrm{r}-65 \mathrm{v}$ & $\begin{array}{l}\text { Auto sacramental de la fe. } \\
\text { Interlocutores son } \\
\text { entendimiento, fe, razón, } \\
\text { ignorancia }\end{array}$ & $\begin{array}{l}\text { Igno. A nuestro amo } \\
\text { entendimiento }\end{array}$ & Hasta que lo vaja a ver & $\begin{array}{l}\text { Acaba amb un «villancicom: «no veo a Dios con } \\
\text { mis ojos / pero daseme a comer / hasta que lo } \\
\text { vaya a ver». }\end{array}$ \\
\hline 25 & $66 \mathrm{r}-68 \mathrm{v}$ & Testamento de Christo & $\begin{array}{l}\text { Quando Dios al hombre } \\
\text { vio }\end{array}$ & Vale por la ley de Dios. & \\
\hline 26 & $70 \mathrm{r}-71 \mathrm{r}$ & Dize Christo al pecador & $\begin{array}{l}\text { Pues cielo, mar y tierra } \\
\text { he yo criado }\end{array}$ & $\begin{array}{l}\text { Ablándanse con fuego y } \\
\text { dolores }\end{array}$ & \\
\hline 27 & $71 \mathrm{v}$ & $\begin{array}{l}\text { Soneto al santíssimo } \\
\text { sacramento }\end{array}$ & En la santa comunión & y llevasse, \&. Fin. & \\
\hline
\end{tabular}

SCRIPTA, Revista internacional de literatura i cultura medieval i moderna, núm. 7 / juny 2016 / pp. 187 - 219 ISSN: 2340-4841 $\cdot$ doi:10.7203/SCRIPTA.7.8476 
Aurèlia Pessarrodona. Ensalades en clausura: Una primera aproximació als cançoners del convent de les carmelites descalces de Santa Teresa de Vic

\begin{tabular}{|c|c|c|c|c|c|}
\hline 28 & $72 \mathrm{r}-72 \mathrm{v}$ & $\begin{array}{l}\text { Glosa de quien podra no } \\
\text { amaros del Santissimo } \\
\text { Sacramento }\end{array}$ & Quien podra no amar? & por me. \&. Fin. & $\begin{array}{l}\text { Quién podrá no amaros és un vilancet de Juan López } \\
\text { de Úbeda (1580) (Serrano Plaja 1943: 56-57). }\end{array}$ \\
\hline 28 & $73 r-75 r$ & $\begin{array}{l}\text { Romance al santíssimo } \\
\text { sacramento al tono y glosa de } \\
\text { en saber la reyna Dido }\end{array}$ & En saber el rey del cielo & $\begin{array}{l}\text { Que es mi sangre } \\
\text { preciada }\end{array}$ & \\
\hline 29 & $75 \mathrm{v}-77 \mathrm{v}$ & Seguidillas al divino & Avesita polida & Que así se acaba. Fin. & \\
\hline 30 & $78 \mathrm{r}-79 \mathrm{r}$ & & Francisco santo glorioso & $\begin{array}{l}\text { Quien soys y quan } \\
\text { venturoso }\end{array}$ & \\
\hline 31 & $79 \mathrm{v}-81 \mathrm{r}$ & Letra del nacimiento de Christo & $\begin{array}{l}\text { A la he que estás } \\
\text { jocundo }\end{array}$ & $\begin{array}{l}\text { Que fuesse Dios, tuvo } \\
\text { el mundo. }\end{array}$ & Arcángel de Alarcón (1594: ff. 351v-353r). \\
\hline 32 & $81 \mathrm{v}-82 \mathrm{v}$ & Villancico al mismo & $\begin{array}{l}\text { Niño aunque tembláis } \\
\text { de frío }\end{array}$ & $\begin{array}{l}\text { De vuestro amor, amor } \\
\text { mío. Fin. }\end{array}$ & \\
\hline 33 & $83 r-84 r$ & Villancico al mismo & Un misterio soberano & $\begin{array}{l}\text { En oyo como la mano. } \\
\text { Fin. }\end{array}$ & \\
\hline 34 & $84 \mathrm{r}-85 \mathrm{v}$ & Otro villancico a lo mismo & $\begin{array}{l}\text { Suplico o, reyna del } \\
\text { cielo }\end{array}$ & Para universal consuelo. & \\
\hline 35 & $86 r-88 r$ & $\begin{array}{l}\text { Letrilla a la Assumption de } \\
\text { Nuestra Señora, en vos de la } \\
\text { santíssima Trinidad y de la } \\
\text { corte soberana }\end{array}$ & En el empíreo se entona & $\begin{array}{l}\text { De Dios virgen } \\
\text { soberana. Fin. }\end{array}$ & \\
\hline 36 & $88 \mathrm{v}-89 \mathrm{r}$ & $\begin{array}{l}\text { A lo mismo en vos de los } \\
\text { Hombres }\end{array}$ & $\begin{array}{l}\text { O quan solos nos } \\
\text { dexáys }\end{array}$ & $\begin{array}{l}\text { La gloria de que gosáys. } \\
\text { Fin. }\end{array}$ & \\
\hline 37 & $89 \mathrm{v}-90 \mathrm{v}$ & Al santíssimo Sacramento & La he si pares mientes & $\begin{array}{l}\text { Tanto más del ambre } \\
\text { sientes. }\end{array}$ & Arcángel de Alarcón (1594: ff. 374r-375v). \\
\hline 38 & $91 \mathrm{r}-92 \mathrm{r}$ & Otras coblas a lo mismo & Del combite desdichado & En un divino bocado. & \\
\hline 39 & $92 \mathrm{r}-93 \mathrm{v}$ & Otras coblas a lo mismo & La misteriosa comida & $\begin{array}{l}\text { El mismo que no } \\
\text { combida }\end{array}$ & Arcángel de Alarcón (1594: ff. 377r-378r). \\
\hline 40 & $93 \mathrm{v}-95 \mathrm{r}$ & $\begin{array}{l}\text { Contienda entre dos pastores } \\
\text { quién es más hermoso St. Joan } \\
\text { Baptista o el Ninyo Jesus, hijo } \\
\text { de María, y al nacimiento }\end{array}$ & $\begin{array}{l}\text { Gil, ¿qué suena en el } \\
\text { ato? }\end{array}$ & No le llegan al capato & $\begin{array}{l}\text { Juan López de Úbeda (1962: 196). } \\
\text { Apareix també en el Cançoner de Valladolid } \\
\text { (García de la Concha, Álvarez Pellitero 1982: } \\
\text { 29). }\end{array}$ \\
\hline 41 & $95 \mathrm{v}-96 \mathrm{r}$ & $\begin{array}{l}\text { Del que dezea ver a Jesús. } \\
\text { Otras coblas }\end{array}$ & Veante mis ojos & Y muérame luego. Fin. & \\
\hline 42 & $96 \mathrm{v}-97 \mathrm{r}$ & $\begin{array}{l}\text { Romance del santíssimo } \\
\text { Sacramento }\end{array}$ & Retraydo está mi Dios & $\begin{array}{l}\text { Muy presto serás } \\
\text { ganado. Fin. }\end{array}$ & \\
\hline
\end{tabular}

\begin{tabular}{|c|c|c|c|c|c|}
\hline 43 & $97 \mathrm{v}-99 \mathrm{r}$ & $\begin{array}{l}\text { Octaba que se halló entre los } \\
\text { papeles del padre fray Luys } \\
\text { Beltrán, del orden de Santo } \\
\text { Domingo }\end{array}$ & $\begin{array}{l}\text { Aquella estrecha qüenta } \\
\text { ánima mía }\end{array}$ & $\begin{array}{l}\text { Que digas muerte ven } \\
\text { en ora buena. Amén. }\end{array}$ & $\begin{array}{l}\text { Apareix en el Cançoner RAE RM 6212, del } \\
\text { primer quart del segle XVII (Aguilar Serrano } \\
\text { 2013: part II, p. } 48, \mathrm{n}^{\circ} 61 \text { ). }\end{array}$ \\
\hline 44 & $\begin{array}{l}99 \mathrm{v}- \\
101 \mathrm{r}\end{array}$ & Soneto en desprecio del mundo & $\begin{array}{l}\text { Pues a quanto el mundo } \\
\text { alaba }\end{array}$ & $\begin{array}{l}\text { Ni quiero bien que se } \\
\text { acaba }\end{array}$ & $\begin{array}{l}\text { Sor Hipòlita de Jesús Rocabertí té un «Himno } \\
\text { en desprecio del mundo» que comença amb la } \\
\text { mateixa quarteta (Serrano 1905: 2,153). }\end{array}$ \\
\hline 45 & $\begin{array}{l}102 \mathrm{r}- \\
102 \mathrm{v}\end{array}$ & Cobles de Sta. Catherina màrtyr & Oiu-nos màrtyr gloriosa & $\begin{array}{l}\text { Verge y màrtyr } \\
\text { Catherina. }\end{array}$ & $\begin{array}{l}\text { Apareix al Llibre de goigs de tots los sants i santes que } \\
\text { avui dia són canonitzats, Ms. } 1052 \text { de la Biblioteca } \\
\text { de la Universitat de Barcelona, pp. 22-23. }\end{array}$ \\
\hline 46 & $\begin{array}{l}103 \mathrm{r}- \\
104 \mathrm{r}\end{array}$ & Para Navidat. Romance & Sale la estrella en oriente & $\begin{array}{l}\text { Dios a su patria } \\
\text { bolvióse }\end{array}$ & $\begin{array}{l}\text { Alonso de Ledesma (1602: 20-24), contrafactum } \\
\text { del romanç de Lope de Vega «Sale la estrella de } \\
\text { Venus». (Romancero general 1600: ff. } 3 \text { c. 1-3). } \\
\text { Querol (1987: II, 26, núm. 67) transcriu una } \\
\text { versió musical que Torrejón de Velasco feu } \\
\text { d'aquest romanç. }\end{array}$ \\
\hline 47 & $105 \mathrm{v}$ & $\begin{array}{l}\text { Romance al sanctíssimo } \\
\text { sacramento }\end{array}$ & En aquel altar de gloria & $\begin{array}{l}\text { Como a perdido } \\
\text { después }\end{array}$ & $\begin{array}{l}\text { En un memorial dels vilancets de Joan Pau } \\
\text { Pujol que tenia el Capítol de la Catedral de } \\
\text { Barcelona, tant de la festivitat del Corpus com } \\
\text { de Nadal, apareix un amb aquest incipit, a vuit } \\
\text { veus (Lambea 1989: 80). }\end{array}$ \\
\hline 48 & $\begin{array}{l}106 \mathrm{v}- \\
107 \mathrm{v}\end{array}$ & Al sanctissimo sacramento & Para sustentarte & Que por sustentarte etc. & $\begin{array}{l}\text { En el Cançoner d'Olot (Biblioteca Pública } \\
\text { d'Olot, Ms. I-VIII, p. 87) es troba una peça } \\
\text { musical amb l'́ncipit «Para sustentarte, gorrona } \\
\text { mía (Lambea 2012: 229). }\end{array}$ \\
\hline 49 & $\begin{array}{l}108 \mathrm{r}- \\
108 \mathrm{v}\end{array}$ & $\begin{array}{l}\text { Romance al santíssimo } \\
\text { Sacramento }\end{array}$ & $\begin{array}{l}\text { De las montañas del } \\
\text { cielo }\end{array}$ & Tu serás sepulcro limpio & $\begin{array}{l}\text { Lope de Vega, El pergegrino en su patria, segona } \\
\text { part (1604). }\end{array}$ \\
\hline 50 & $\begin{array}{l}109 \mathrm{r}- \\
113 \mathrm{v}\end{array}$ & Ensaladilla del retablo & $\begin{array}{l}\text { Tocando en un } \\
\text { tamborino }\end{array}$ & $\begin{array}{l}\text { Vengan mañana } \\
\text { temprano }\end{array}$ & José de Valdivielso (1880: $307-312$ ) \\
\hline
\end{tabular}

SCRIPTA, Revista internacional de literatura i cultura medieval i moderna, núm. 7 / juny 2016 / pp. 187 - 219 
Aurèlia Pessarrodona. Ensalades en clausura: Una primera aproximació als cançoners del convent de les carmelites descalces de Santa Teresa de Vic

\begin{tabular}{|c|c|c|c|c|c|c|}
\hline 51 & $\begin{array}{l}113 \mathrm{v}- \\
116 \mathrm{v}\end{array}$ & Navidad. Inc. & Yo me iva Bartolo & $\begin{array}{l}\text { Quiere hazer hostias } \\
\text { zon zon. }\end{array}$ & José de Valdivielso (1680: 339-344). & \\
\hline 52 & $\begin{array}{l}{[117 \mathrm{r}]-} \\
{[118 \mathrm{r}]}\end{array}$ & Coblas de Nativitat & Vos pariste madre & $\begin{array}{l}\text { que amargamente } \\
\text { quebra }\end{array}$ & $\begin{array}{l}\text { Comença en el f. [117r] amb dos versos finals } \\
\text { d'una obra desconeguda. }\end{array}$ & $2^{2}$ mà \\
\hline 53 & $\begin{array}{l}{[119 \mathrm{r}]-} \\
{[120 \mathrm{v}]}\end{array}$ & $\begin{array}{l}\text { Coblas de Nativitat, Romance a } \\
\text { una alma enferma de amor y } \\
\text { ausencia }\end{array}$ & A la regalada esposa & $\begin{array}{l}\text { Te podrás levantar } \\
\text { buena }\end{array}$ & Valdivielso (1880: 231-233). & $3^{a}$ mà \\
\hline 54 & $\begin{array}{l}{[121 \mathrm{r}]-} \\
{[123 \mathrm{r}]}\end{array}$ & & $\begin{array}{l}\text { Que ynportan bienes del } \\
\text { suelo }\end{array}$ & $\begin{array}{l}\text { Ni avéys de castigarme } \\
\text { ni ofenderos }\end{array}$ & & \multirow[t]{3}{*}{$4^{2} \mathrm{mà}$} \\
\hline 55 & {$[124 \mathrm{v}]$} & $\begin{array}{l}\text { Liras de Dios a una alma } \\
\text { ingrata y que mucho le a } \\
\text { ofendido }\end{array}$ & $\begin{array}{l}\text { Respóndeme alma } \\
\text { ingrata qué te ccho }\end{array}$ & $\begin{array}{l}\text { Mas tus misericordias } \\
\text { son mayores }\end{array}$ & & \\
\hline 56 & 10 f.s.n. & $\begin{array}{l}\text { Jesús, Maria, Joseph. Exercisio } \\
\text { spiritual del Padre Fray } \\
\text { Francischo del Santo } \\
\text { Sacramento }\end{array}$ & $\begin{array}{l}\text { Quan bueno sea hacer } \\
\text { conciertos spirituales }\end{array}$ & & & \\
\hline
\end{tabular}

SCRIPTA, Revista internacional de literatura i cultura medieval i moderna, núm. 7 / juny 2016 / pp. 187 - 219 ISSN: 2340-4841 $\cdot$ doi:10.7203/SCRIPTA.7.8476 
Aurèlia Pessarrodona. Ensalades en clausura: Una primera aproximació als cançoners del convent de les carmelites descalces de Santa Teresa de Vic

Apèndix II: taula del contingut del Cançoner Ms. 2 (ACDV)

\begin{tabular}{|c|c|c|c|c|c|c|}
\hline [Núm.] & Fols. & Rúbrica & Íncipit & Exxplicit & $\begin{array}{l}\text { Autoria } \mathrm{i} / \mathrm{o} \text { referències. Altres } \\
\text { observacions }\end{array}$ & Mà $\dot{a}^{33}$ \\
\hline & & & & & $\begin{array}{l}\text { En el full enganxat a la coberta de pergamí } \\
\text { una composició: Romance de gracia recién } \\
\text { entrada en la religión. }\end{array}$ & \\
\hline & $1 \mathrm{r}$ & $\begin{array}{l}\text { A la madre }[\ldots] \text { Carmelitas } \\
\text { descalza Sta. Teresa Vich. }\end{array}$ & & & & $5^{2}$ mà \\
\hline 1 & $2 \mathrm{r}-4 \mathrm{v}$ & & $\begin{array}{l}\text { Este libro va sin } \\
\text { nombre }\end{array}$ & $\begin{array}{l}\text { Y la purga viene cerca. } \\
\text { Fin. }\end{array}$ & & \multirow[t]{7}{*}{$6^{2}$ mà } \\
\hline 2 & $5 r-7 r$ & Romançe a la eleçión de Perlada & En el sitio más ameno & $\begin{array}{l}\text { Para enternecer las } \\
\text { almas }\end{array}$ & $\begin{array}{l}\text { Inici f. 6r: «Mil veces en hora buena / } \\
\text { dulce madre Mariana / de tales súbditas } \\
\text { seas / meritissima Prelada». } \\
\text { Podria tractar-se de Mariana de San José, } \\
\text { de Mur Ripol, natural de Tarazona, que va } \\
\text { entrar al convent de San José de Saragossa } \\
\text { l'any } 1615 \text { i la seva comunitat va voler que } \\
\text { fos prelada, però ella s'hi negà per la seva } \\
\text { humilitat (Lanuza 1659: 416). }\end{array}$ & \\
\hline 3 & $7 \mathrm{r}-7 \mathrm{v}$ & Villançico a la klenda & Çagalejas del Carmelo & $\begin{array}{l}\text { Que es un retrato del } \\
\text { çielo. Fin. }\end{array}$ & & \\
\hline 4 & $8 \mathrm{r}-9 \mathrm{v}$ & $\begin{array}{l}\text { Romançe al sanctíssimo } \\
\text { Sacramento }\end{array}$ & $\begin{array}{l}\text { Pues cabe en mi buena } \\
\text { dicha }\end{array}$ & $\begin{array}{l}\text { Y se que te preçias } \\
\text { dello. Laus deo. }\end{array}$ & & \\
\hline 5 & $10-11 \mathrm{r}$ & $\begin{array}{l}\text { Romançe al sanctíssimo } \\
\text { sacramento }\end{array}$ & Hostia pura consagrada & $\begin{array}{l}\text { Mi alma a reçevirte } \\
\text { como debe. }\end{array}$ & & \\
\hline 6 & $11 \mathrm{r}-11 \mathrm{v}$ & $\begin{array}{l}\text { Lira en esdrúxolo a la } \\
\text { Circunçission }\end{array}$ & En la sangre puríssima & $\begin{array}{l}\text { Al último blasón de sus } \\
\text { azañas. Fin. }\end{array}$ & & \\
\hline 7 & $12 \mathrm{r}-12 \mathrm{v}$ & $\begin{array}{l}\text { Al hábito de la hermana } \\
\text { Catalina de Jesús María. } \\
\text { Villancico }\end{array}$ & Bien negociáis Catalina & $\begin{array}{l}\text { Gloria humana por } \\
\text { divina }\end{array}$ & $\begin{array}{l}\text { A Vic hi havia una Caterina de Jesús } \\
\text { Maria, Bigas Riera (1617-1655; V. } 1638 . \\
\text { P.1639) però no és segur que sigui ella }\end{array}$ & \\
\hline
\end{tabular}

33 Es continúa la numeració de l'anterior taula.

\begin{tabular}{|c|c|c|c|c|c|}
\hline 8 & $12 \mathrm{v}-13 \mathrm{r}$ & $\begin{array}{l}\text { Otro a la entrada de la hermana } \\
\text { Josepha de la Encarnación }\end{array}$ & Ojos de linçe tenéis & $\begin{array}{l}\text { Y el cielo lo que } \\
\text { escogéis. Fin. }\end{array}$ & Josefa de l'Encarnació? \\
\hline 9 & $13 \mathrm{v}$ & $\begin{array}{l}\text { Villancico al hábito de doña } \\
\text { Mariana de Torrellas }\end{array}$ & No sin particular lux & Con el nombre de Jesús & $\begin{array}{l}\text { Ana María de Jesús, priora del convent de } \\
\text { San José de Saragossa, filla de Beatriz de } \\
\text { Alagon (Lanuza 1638: índex; 1659: 395- } \\
\text { 414). }\end{array}$ \\
\hline 10 & $14 \mathrm{r}$ & $\begin{array}{l}\text { Otro al velo de la hermana } \\
\text { Teresa }\end{array}$ & Tomad el velo Teresa & $\begin{array}{l}\text { Que es gloria de vuestra } \\
\text { empresa. }\end{array}$ & Vàries tereses... \\
\hline 11 & $14 \mathrm{v}-15 \mathrm{r}$ & $\begin{array}{l}\text { Otro villancico a la entrada o } \\
\text { velo de dos }\end{array}$ & $\begin{array}{l}\text { A Dios dos fieles } \\
\text { esposas }\end{array}$ & $\begin{array}{l}\text { Aunque Racheles } \\
\text { hermosas. }\end{array}$ & \multirow[t]{2}{*}{ Anna de San Elías i Luisa de Santa Teresa? } \\
\hline 12 & $15 \mathrm{v}-17 \mathrm{r}$ & $\begin{array}{l}\text { A las mismas romance. Anna de } \\
\text { San Elias y Luysa de santa } \\
\text { Teresa }\end{array}$ & Del divino amor heridas & $\begin{array}{l}\text { Que el amor que le } \\
\text { tienen les da desmayo. } \\
\text { Fin. }\end{array}$ & \\
\hline 13 & $17 \mathrm{v}-18 \mathrm{r}$ & Al sanctíssimo sacramento & $\begin{array}{l}\text { Tan hermosa y blanca } \\
\text { estáis }\end{array}$ & $\begin{array}{l}\text { Y del alma que animáis. } \\
\text { Fin. }\end{array}$ & \\
\hline 14 & $18 \mathrm{v}-19 \mathrm{v}$ & $\begin{array}{l}\text { Romançe a la beatificaçión de } \\
\text { nuestra santa madre. }\end{array}$ & Aquel thesoro divino & $\begin{array}{l}\text { Pues da más luz que el } \\
\text { sol y más que el alba. }\end{array}$ & \\
\hline 15 & $20 \mathrm{r}-21 \mathrm{r}$ & A la misma sta. & $\begin{array}{l}\text { Hoy muestra el cielo a } \\
\text { los Hombres }\end{array}$ & $\begin{array}{l}\text { Con tan cortas } \\
\text { alabanças. }\end{array}$ & \\
\hline 16 & $21 \mathrm{r}-21 \mathrm{v}$ & Villançico a la misma & Hiço el amor una cosa & $\begin{array}{l}\text { Mujer toda poderosa. } \\
\text { Fin. }\end{array}$ & \\
\hline 17 & $22 \mathrm{r}-23 \mathrm{v}$ & $\begin{array}{l}\text { Canción al alto y levantado } \\
\text { intento que nuestra madre santa } \\
\text { Teresa tuvo en haçer sus } \\
\text { fundaçiones }\end{array}$ & $\begin{array}{l}\text { Confieso que } \\
\text { empobrece }\end{array}$ & $\begin{array}{l}\text { Mil almas esta imbita } \\
\text { capitana. }\end{array}$ & \\
\hline 18 & $23 \mathrm{v}$ & & Canción recoge el paso & $\begin{array}{l}\text { Venir a morir pobre al } \\
\text { hospital }\end{array}$ & \\
\hline 19 & $23 \mathrm{v}-24 \mathrm{v}$ & $\begin{array}{l}\text { Romance a Santa Teresa de } \\
\text { Jesús, patrona de Castilla y } \\
\text { mayplus }\end{array}$ & Entre sonoros clarines & $\begin{array}{l}\text { Viva pues vive en Dios, } \\
\text { y Dios en ella. }\end{array}$ & \\
\hline 20 & $24 \mathrm{v}-25 \mathrm{v}$ & $\begin{array}{l}\text { Otro a la misma virgen que se } \\
\text { cantó en su fiesta el año } 1626 \\
\text { en su casa Çaragoza }\end{array}$ & $\begin{array}{l}\text { El sol de nuestro } \\
\text { emispherio }\end{array}$ & $\begin{array}{l}\text { Que en fuego de amor } \\
\text { divino arde Teresa. }\end{array}$ & \\
\hline 21 & $25 \mathrm{v}-26 \mathrm{r}$ & Villancico a la misma patrona & Dicen Teresa de vos & $\begin{array}{l}\text { Sino al verdadero Dios. } \\
\text { Fin. Laus Deo. }\end{array}$ & \\
\hline 22 & $26 \mathrm{v}-27 \mathrm{v}$ & $\begin{array}{l}\text { Romançe a la pasión de } \\
\text { Nuestro Señor }\end{array}$ & Es para mi tu pasión & Es el dueño de mi alma. & \\
\hline
\end{tabular}

SCRIPTA, Revista internacional de literatura i cultura medieval i moderna, núm. 7 / juny 2016 / pp. 187 - 219 ISSN: 2340-4841 · doi:10.7203/SCRIPTA.7.8476 
Aurèlia Pessarrodona. Ensalades en clausura: Una primera aproximació als cançoners del convent de les carmelites descalces de Santa Teresa de Vic

\begin{tabular}{|c|c|c|c|c|c|}
\hline 23 & $27 \mathrm{v}-28 \mathrm{v}$ & Otro & $\begin{array}{l}\text { Sonrrosado el rostro } \\
\text { hermoso }\end{array}$ & $\begin{array}{l}\text { Dicho en solo una } \\
\text { palabra. }\end{array}$ & \\
\hline 24 & $28 \mathrm{v}-30 \mathrm{r}$ & Otro & $\begin{array}{l}\text { El ángel del gran } \\
\text { consejo }\end{array}$ & $\begin{array}{l}\text { Ençierre en sus trojes } \\
\text { grano. Fin. }\end{array}$ & \\
\hline 25 & $30 \mathrm{v}-31 \mathrm{v}$ & Romançe a la muerte de Christo & A morir vais señor mío & $\begin{array}{l}\text { Aunque sea vuestro } \\
\text { reyno. }\end{array}$ & \\
\hline 26 & $31 \mathrm{v}-33 \mathrm{r}$ & Al Ecce Homo & $\begin{array}{l}\text { Un hombre muestra } \\
\text { Pilatos }\end{array}$ & $\begin{array}{l}\text { Haçemos de esclavos } \\
\text { hijos. }\end{array}$ & \\
\hline 27 & $33 r-35 r$ & A la Soledad. Otro. & Libertad que aflige tanto & $\begin{array}{l}\text { Cursaron seré yo una. } \\
\text { Finis Laus Deo. }\end{array}$ & $\begin{array}{l}\text { Contrafactum del romanç Las niñas } \\
\text { guardadas, que comença amb «Soledad que } \\
\text { aflije tanto» (Romancero general 1604: part } \\
8^{8} \text { ). }\end{array}$ \\
\hline 28 & $35 r-36 r$ & $\begin{array}{l}\text { Romançe a una tribunica donde } \\
\text { se hazen exerçiçios }\end{array}$ & $\begin{array}{l}\text { Ya buelvo tribuna } \\
\text { amada }\end{array}$ & $\begin{array}{l}\text { La regalada y la visita. } \\
\text { Fin. }\end{array}$ & \\
\hline 29 & $36 \mathrm{r}-37 \mathrm{v}$ & Seguidillas para la labor & $\begin{array}{l}\text { Quien a su Dios tiene } \\
\text { nada le falta }\end{array}$ & $\begin{array}{l}\text { Serafines le sirven con } \\
\text { reverencia. }\end{array}$ & $\begin{array}{l}\text { Basat en el poema de Santa Teresa de } \\
\text { Jesús Nada te turbe. }\end{array}$ \\
\hline 30 & $38 \mathrm{r}-39 \mathrm{r}$ & Diálogo al Nacimiento & $\begin{array}{l}\text { Bras. El niño Dios se ha } \\
\text { dormido }\end{array}$ & Ya por verle me muero. & \\
\hline 31 & $39 \mathrm{r}-40 \mathrm{r}$ & Quintillas al Nacimiento & $\begin{array}{l}\text { Hecho criatura el } \\
\text { creador }\end{array}$ & $\begin{array}{l}\text { Y niño porque le } \\
\text { abraçe }\end{array}$ & \\
\hline 32 & $40 \mathrm{r}-41 \mathrm{r}$ & Villancico al Nacimiento & Un niño nace en Belén & Mirad si me quiere bien. & \\
\hline 33 & $41 \mathrm{r}-47 \mathrm{v}$ & $\begin{array}{l}\text { Un diálogo entre dos pastores } \\
\text { en una festecica a la misma } \\
\text { fiesta y algunos ofreçimientos. } \\
\text { Loa }\end{array}$ & $\begin{array}{l}\text { En aquestes deesas tan } \\
\text { amenas }\end{array}$ & $\begin{array}{l}\text { Os la ofrezco. Fin. Laus } \\
\text { Deo. }\end{array}$ & \\
\hline 34 & $48 \mathrm{r}-48 \mathrm{v}$ & Déçimas al Nacimiento & $\begin{array}{l}\text { Quien os viere en un } \\
\text { portal }\end{array}$ & $\begin{array}{l}\text { Lo bueno que hay entre } \\
\text { nos. Finis laus Deo. }\end{array}$ & \\
\hline 35 & $48 \mathrm{v}-50 \mathrm{v}$ & A la Çircunçisión & Luz de los ojos de Dios & $\begin{array}{l}\mathrm{O} \text {, morir porque no } \\
\text { muero. }\end{array}$ & \\
\hline 36 & $50 \mathrm{v}-52 \mathrm{v}$ & A la huida a Egipto & Por ver y poder servir & A los desterrados della. & \\
\hline 37 & $52 \mathrm{v}-53 \mathrm{v}$ & Al desposorio de la Virgen & Una nina de treçe años & Sus plantas bellas. & \\
\hline 38 & $53 \mathrm{v}-56 \mathrm{v}$ & $\begin{array}{l}\text { Romance de recién entrada en } \\
\text { la religión }\end{array}$ & $\begin{array}{l}\text { Hechada en un pobre } \\
\text { lecho }\end{array}$ & Gana infinitas riquezas. & $\begin{array}{l}\text { Primers versos: «Hechada en un pobre } \\
\text { lecho / de pobres pajas y jerga / esta } \\
\text { Anna pobre y descalça / virtiendo } \\
\text { lagrimas tiernas.» }\end{array}$ \\
\hline
\end{tabular}

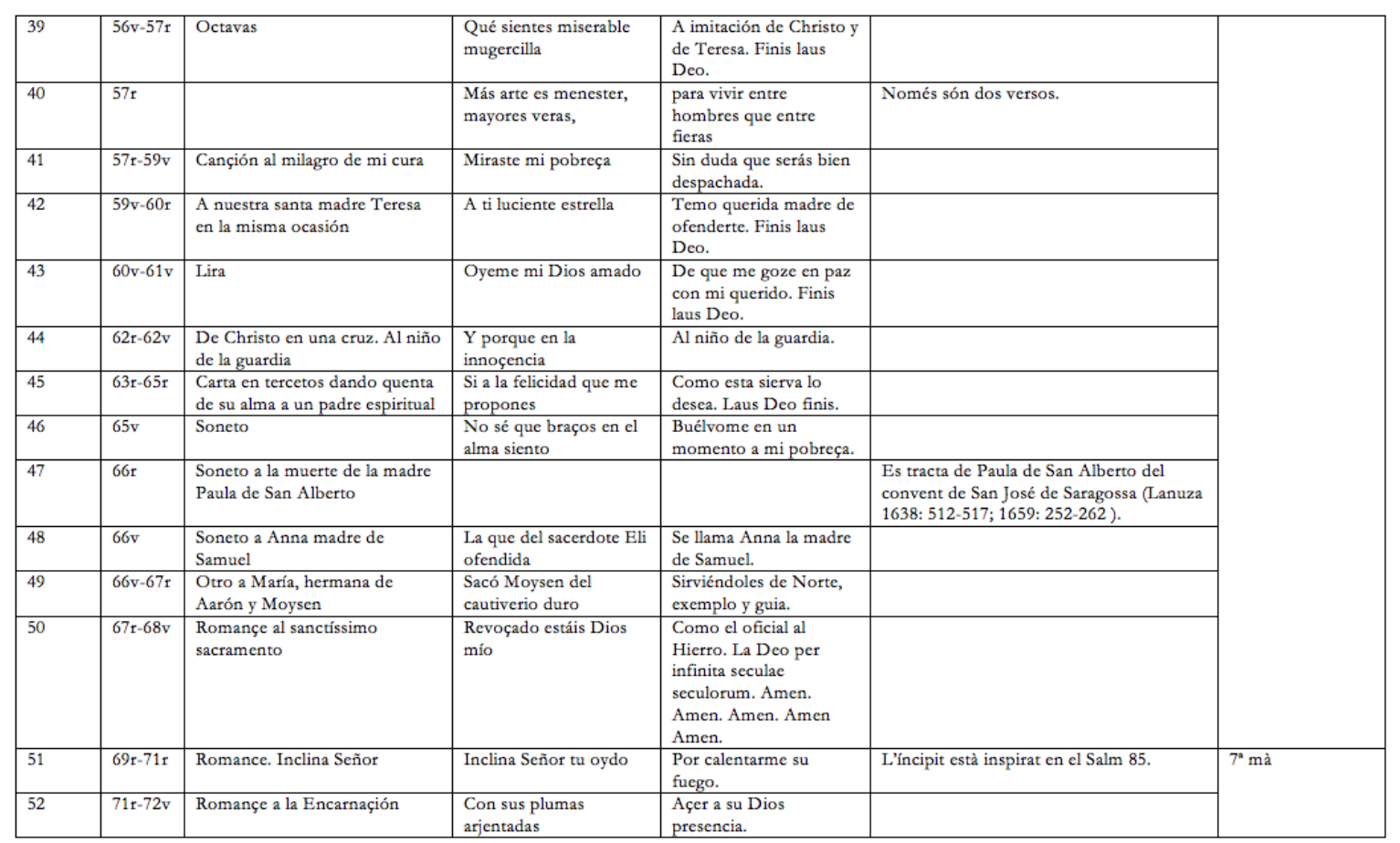

SCRIPTA, Revista internacional de literatura i cultura medieval i moderna, núm. 7 / juny 2016 / pp. 187 - 219 ISSN: 2340-4841 $\cdot$ doi:10.7203/SCRIPTA.7.8476 
Aurèlia Pessarrodona. Ensalades en clausura: Una primera aproximació als cançoners del convent de les carmelites descalces de Santa Teresa de Vic

\begin{tabular}{|c|c|c|c|c|c|c|}
\hline 53 & $72 \mathrm{v}-75 \mathrm{r}$ & Romançe a la fiesta de la $\mathrm{O}$. & Hun alma en la soledad & $\begin{array}{l}\text { Ben y en mi alma } \\
\text { reposa. }\end{array}$ & & \\
\hline 54 & $75 r-78 r$ & $\begin{array}{l}\text { Romançe al santísimo } \\
\text { Nacimiento }\end{array}$ & De la flor de Nazarén & $\begin{array}{l}\text { Por tan summo } \\
\text { beneficio. }\end{array}$ & & \\
\hline 55 & $78 \mathrm{r}-80 \mathrm{v}$ & $\begin{array}{l}\text { Romance a la Purificación de } \\
\text { Virjen nuestra señora }\end{array}$ & $\begin{array}{l}\text { Oy en el templo se } \\
\text { ofrece }\end{array}$ & $\begin{array}{l}\text { Con ser la misma } \\
\text { pareça. }\end{array}$ & & \\
\hline 56 & $80 \mathrm{v}-82 \mathrm{v}$ & Romance en los ejerçi[ci]os & $\begin{array}{l}\text { Al rresplandor de la } \\
\text { gloria }\end{array}$ & La rredimiste muriendo. & & \\
\hline 57 & $82 \mathrm{v}-84 \mathrm{r}$ & $\begin{array}{l}\text { Romançe al santísimo } \\
\text { Sacramento }\end{array}$ & $\begin{array}{l}\text { Que sea mil veces } \\
\text { alabado }\end{array}$ & $\begin{array}{l}\text { Yo lloro bida mía } \\
\text { buestras ofensas. }\end{array}$ & & \\
\hline 58 & $84 r-87 r$ & Romançe vuelto a lo divino & $\begin{array}{l}\text { Qué ynporta que mi } \\
\text { raçon }\end{array}$ & $\begin{array}{l}\text { Goçando del bien que } \\
\text { amamos. }\end{array}$ & & \\
\hline 59 & $87 \mathrm{v}-89 \mathrm{r}$ & Endechas & Quando Dios amado & De tu gloria eterna. & & \\
\hline 60 & $89 \mathrm{r}-91 \mathrm{r}$ & $\begin{array}{l}\text { Romançe al santíssimo } \\
\text { Sacramento }\end{array}$ & Oy sale en público el rey & Gisado a vuestro sabor. & & \\
\hline 61 & $91 \mathrm{r}-92$ & Otro a lo mismo & $\begin{array}{l}\text { Desde unas bandas de } \\
\text { flores }\end{array}$ & A todos quantos miráys. & & \\
\hline 62 & $92 \mathrm{r}-94 \mathrm{v}$ & $\begin{array}{l}\text { Otro a san Viçente mártir } \\
\text { español }\end{array}$ & El baleroso español & suba a ser glorificado. & & \\
\hline 63 & $\begin{array}{l}95 \mathrm{r}- \\
101 \mathrm{r}\end{array}$ & Romançe a San Ignaçio & $\begin{array}{l}\text { Enbarcándome en el } \\
\text { mar }\end{array}$ & $\begin{array}{l}\text { Del padre eterno y } \\
\text { aeterna. Fin laus Deo. }\end{array}$ & Falten els ff. 99 i 100. & \\
\hline 64 & $101 \mathrm{v}$ & Soneto & $\begin{array}{l}\text { Cuando a tu luz mi } \\
\text { amado Dios me beo }\end{array}$ & $\begin{array}{l}\text { Cuánto más ama más } \\
\text { amor desea }\end{array}$ & & $8^{\mathrm{a}}$ mà \\
\hline 65 & $\begin{array}{l}102 \mathrm{r}- \\
103 \mathrm{v}\end{array}$ & $\begin{array}{l}\text { Romance sobre el salmo 21, } \\
\text { Deus deus meus }\end{array}$ & $\begin{array}{l}\text { Dios y dos veses Dios } \\
\text { mío }\end{array}$ & $\begin{array}{l}\text { Confecere er de açero. } \\
\text { Finis }\end{array}$ & & $9^{\mathrm{a}}$ mà (4 $4^{2}$ ?) \\
\hline 66 & $\begin{array}{l}104 \mathrm{r}- \\
106 \mathrm{v}\end{array}$ & $\begin{array}{l}\text { Romance en que prosigue el } \\
\text { salmo }\end{array}$ & Seca y flaca mi birtud & Obrando tales fineças. & & $8^{\mathrm{a}}$ mà \\
\hline 67 & $\begin{array}{l}107 \mathrm{v}- \\
109 \mathrm{r}\end{array}$ & Romançe a los santos rreies & Con aparato rreal & $\begin{array}{l}\text { Si a gosarlo se disponen. } \\
\text { Finis. }\end{array}$ & & $10^{\mathrm{a}} \mathrm{mà}$ \\
\hline 68 & $\begin{array}{l}109 \mathrm{v}- \\
110 \mathrm{v}\end{array}$ & $\begin{array}{l}\text { Letrilla a nuestra santa madre } \\
\text { Teresa de Jesús }\end{array}$ & A del Carmelo & $\begin{array}{l}\text { Guarde Dios tan àrdua } \\
\text { empresa. }\end{array}$ & & $9^{\mathrm{a}}$ mà (4 $4^{\mathrm{a}}$ ) \\
\hline 69 & $\begin{array}{l}111 \mathrm{r}- \\
111 \mathrm{v}\end{array}$ & $\begin{array}{l}\text { Letrilla a nuestra santa madre } \\
\text { Teresa de Jesús }\end{array}$ & $\begin{array}{l}\text { El monte que fue de } \\
\text { Elias }\end{array}$ & $\begin{array}{l}\text { Viva, viva, repiten la } \\
\text { reforma. Finis. }\end{array}$ & & \\
\hline 70 & $\begin{array}{l}112 \mathrm{r}- \\
113 \mathrm{v}\end{array}$ & $\begin{array}{l}\text { Octavas de nuestra santa madre } \\
\text { Teresa de Jesús }\end{array}$ & $\begin{array}{l}\text { Desid cielos y tierra, } \\
\text { desid mares }\end{array}$ & $\begin{array}{l}\text { Serás dulse paraíso duro } \\
\text { infierno }\end{array}$ & Poema de Santa Teresa de Jesús & $11^{2}$ mà \\
\hline
\end{tabular}

\begin{tabular}{|c|c|c|c|c|c|c|}
\hline 71 & $\begin{array}{l}114 \mathrm{r}- \\
116 \mathrm{v}\end{array}$ & Loa & $\begin{array}{l}\text { No salgo a pedir que } \\
\text { callen }\end{array}$ & Con el niño rey eterno. & $\begin{array}{l}\text { Guarda moltes similituds amb la lloa de } E l \\
\text { amor constante de Guillén de Castro (entre } \\
1596 \text { i 1599) (1997: 4-115) }\end{array}$ & $12^{\mathrm{a}}$ mà \\
\hline 72 & $\begin{array}{l}117 \mathrm{v}- \\
119 \mathrm{r}\end{array}$ & $\begin{array}{l}\text { Para despertad a maytines en la } \\
\text { noche de nabidad }\end{array}$ & Si? Hija del Carmelo & Verdadera y suma alteza & & $13^{\mathrm{a}} \mathrm{mà}$ \\
\hline 73 & $\begin{array}{l}119 \mathrm{v}- \\
121 \mathrm{v}\end{array}$ & $\begin{array}{l}\text { Romanca de doña Margarita de } \\
\text { Austria y serenisima infanta de } \\
\text { Ungría y Boemia }\end{array}$ & En la nave de la yglesia & Vale un ojo de la cara & & \multirow[t]{6}{*}{$14^{\mathrm{a}}$ mà } \\
\hline 74 & $\begin{array}{l}121 \mathrm{v}- \\
123 \mathrm{v}\end{array}$ & Otro romance a una real señora & Ausente del caro espós & A su esposo cara a cara & $\begin{array}{l}\text { Tracta de «Doña Felipa Jesus / de la } \\
\text { sangre lusitana / visnieta del Rey manuel / } \\
\text { y sobrino [sic] del de españa». Podria ser } \\
\text { Felipa Jesús de Portugal (1560-?), filla } \\
\text { d’Antonio de Portugal, prior de Crato. }\end{array}$ & \\
\hline 75 & $\begin{array}{l}124 \mathrm{r}- \\
125 \mathrm{v}\end{array}$ & $\begin{array}{l}\text { Romançe dando a la Virgen } \\
\text { madre de Dios la enorabuena } \\
\text { del nacimiento de su hijo y } \\
\text { redentor nuestro señor } \\
\text { Jesuchristo }\end{array}$ & Ame cabido por suerte & $\begin{array}{l}\text { ser del rey divino madre } \\
\text { y doncella. }\end{array}$ & & \\
\hline 76 & $\begin{array}{l}126 \mathrm{v}- \\
127 \mathrm{v}\end{array}$ & $\begin{array}{l}\text { Romance narando un hurto que } \\
\text { con singular contrición confesó } \\
\text { nuestra hermana Ysabel de los } \\
\text { Ángeles, es de entretenimiento } \\
\text { y gracia. }\end{array}$ & $\begin{array}{l}\text { Es nuestra hermana } \\
\text { Ysabel }\end{array}$ & $\begin{array}{l}\text { De hazer coblas me } \\
\text { despido. Finis }\end{array}$ & $\begin{array}{l}\text { Al convent de Santa Teresa de Vic hi } \\
\text { hagué una Isabel dels Ȧngels, Mora, viuda } \\
\text { Pujalt (1632-1667; vestició: 28-03-1638; } \\
\text { professió: 08-04-1639) }\end{array}$ & \\
\hline 77 & $\begin{array}{l}128 \mathrm{v}- \\
136 \mathrm{v}\end{array}$ & $\begin{array}{l}\text { Romance a la entrada en el } \\
\text { convento de las carmelitas } \\
\text { descalças de la hermana María } \\
\text { de Jesus de la ciudad de } \\
\text { Barcelona }\end{array}$ & $\begin{array}{l}\text { De mi llugar vendo a } \\
\text { pie }\end{array}$ & $\begin{array}{l}\text { Y a vos suplico lo } \\
\text { mesmo. }\end{array}$ & $\begin{array}{l}\text { ¿Seria Maria de Jesús, Ramon Ayllà (ca. } \\
\text { 1629-1705), que professà el } 1648 \text { al } \\
\text { Convent de la Puríssima Concepció de } \\
\text { Barcelona? }\end{array}$ & \\
\hline 78 & $\begin{array}{l}137 \mathrm{r}- \\
138 \mathrm{v}\end{array}$ & & Óyeme çagala hermosa & Agas la quenta. & & \\
\hline 79 & $\begin{array}{l}139 \mathrm{r}- \\
140 \mathrm{r}\end{array}$ & $\begin{array}{l}\text { Romanze de una alma que trajo } \\
\text { Dios del siglo a la religión de } \\
\text { carmelitas descalças y lo } \\
\text { compuso en egerçiçios }\end{array}$ & $\begin{array}{l}\text { Dios ynmenso y } \\
\text { poderoso }\end{array}$ & $\begin{array}{l}\text { Y el conerbarme en tu } \\
\text { gracia. Laus Deo. }\end{array}$ & & $\begin{array}{l}15^{\mathrm{a}} \text { mà (convent } \\
\text { de Vic) }\end{array}$ \\
\hline 80 & $\begin{array}{l}140 \mathrm{v}- \\
141 \mathrm{r}\end{array}$ & $\begin{array}{l}\text { Petición que hizo una religiosa } \\
\text { descalza a otra que estaba en } \\
\text { egerçiçios }\end{array}$ & $\begin{array}{l}\text { Llegando a pidir } \\
\text { licencia. }\end{array}$ & $\begin{array}{l}\text { A Él solo contemples o } \\
\text { ames. Fin. }\end{array}$ & & $\begin{array}{l}\text { Esperança de } \\
\text { Jesús, Metge i } \\
\text { Forns (1624-1681). }\end{array}$ \\
\hline
\end{tabular}

SCRIPTA, Revista internacional de literatura i cultura medieval i moderna, núm. 7 / juny 2016 / pp. 187 - 219 ISSN: 2340-4841 · doi:10.7203/SCRIPTA.7.8476 
Aurèlia Pessarrodona. Ensalades en clausura: Una primera aproximació als cançoners del convent de les carmelites descalces de Santa Teresa de Vic

\begin{tabular}{|c|c|c|c|c|c|c|}
\hline 81 & $\begin{array}{l}142 \mathrm{r}- \\
143 \mathrm{v}\end{array}$ & $\begin{array}{l}\text { Romanze de gracia recién } \\
\text { entrada en la religión la madre } \\
\text { Anna de la Madre de Dios }\end{array}$ & $\begin{array}{l}\text { Sentaos aquí, querpo } \\
\text { mío }\end{array}$ & $\begin{array}{l}\text { Me que hable y } \\
\text { çiéranme los labios. }\end{array}$ & $\begin{array}{l}\text { Al convent de San José de Saragossa } \\
\text { consta una Ana de la Madre de Dios, que } \\
\text { va prendre l'hàbit de part de la fundadora } \\
\text { Isabel de Santo Domingo (Lanuza 1659: } \\
\text { 232-239). }\end{array}$ & $\begin{array}{l}\text { Vestició: 21-12- } \\
\text { 1640. Professió: } \\
\text { 23-12-1641 }\end{array}$ \\
\hline 82 & $\begin{array}{l}144 \mathrm{r}^{-} \\
145 \mathrm{r}\end{array}$ & $\begin{array}{l}\text { Loa para la entrada de alguna } \\
\text { nobiçia en la religión }\end{array}$ & En el sitio más ameno & $\begin{array}{l}\text { Me esperan las çagalas. } \\
\text { Fin. }\end{array}$ & Els primers versos són com els del núm. 3 & \\
\hline 83 & $\begin{array}{l}146 r- \\
147 r\end{array}$ & $\begin{array}{l}\text { Villancico para la noche de } \\
\text { Nabidad }\end{array}$ & Vamos çagalas apriesa & $\begin{array}{l}\text { De las hijas de Theresa. } \\
\text { Fin. }\end{array}$ & & \\
\hline 84 & $\begin{array}{l}147 \mathrm{r}- \\
148 \mathrm{r}\end{array}$ & $\begin{array}{l}\text { Villançico al velo de la hermana } \\
\text { Theresa de San Joseph }\end{array}$ & $\begin{array}{l}\text { Estribillo. Sol flamante } \\
\text { que en giro de luzes }\end{array}$ & $\begin{array}{l}\text { Queda el mundo en } \\
\text { vencimiento }\end{array}$ & $\begin{array}{l}\text { Teresa de Sant Josep, Bojons Sala (1652- } \\
\text { 1713). Vestició: 30-08-1670. Professió: 05- } \\
09-1671 \text {. }\end{array}$ & \multirow{2}{*}{$\begin{array}{l}\text { Maria de la } \\
\text { Concepció, Palau } \\
\text { (1629-1703). } \\
\text { Vestició: 17-11- } \\
\text { 1644. Professió: } \\
\text { 10-12-1645. }\end{array}$} \\
\hline 85 & $\begin{array}{l}148 \mathrm{r}- \\
149 \mathrm{v}\end{array}$ & Otro villancico a la mesma & $\begin{array}{l}\text { Estribillo. Zagalejas de } \\
\text { Elías al monte }\end{array}$ & $\begin{array}{l}\text { Zagaleja al monte que } \\
\text { llaman. Finis }\end{array}$ & & \\
\hline 86 & $\begin{array}{l}150 \mathrm{r}- \\
150 \mathrm{v}\end{array}$ & $\begin{array}{l}\text { De esta letra primera nuestra } \\
\text { seráfica madre santa Teresa de } \\
\text { Jesús }\end{array}$ & $\begin{array}{l}\text { Estribillo. Temple } \\
\text { serafin el dardo con }\end{array}$ & $\begin{array}{l}\text { Herida de amores la } \\
\text { muerte es vivir. Fin. }\end{array}$ & & $\begin{array}{l}\text { Teresa de Sant } \\
\text { Josep, Bojons Sala }\end{array}$ \\
\hline 87 & $\begin{array}{l}151 \mathrm{r}- \\
151 \mathrm{v}\end{array}$ & Letra a nuestra santa madre & $\begin{array}{l}\text { Hiere amor, aunque tan } \\
\text { tierno }\end{array}$ & $\begin{array}{l}\text { Las letras que ella te dio. } \\
\text { Fin. }\end{array}$ & & \multirow{2}{*}{$\begin{array}{l}\text { Francesca de la } \\
\text { Verge, Vila Bauló } \\
(1648-1716) \text {. } \\
\text { Vestició: 14-08- } \\
\text { 1664. Professió: } \\
\text { 08-09-1665. }\end{array}$} \\
\hline 88 & $\begin{array}{l}152 \mathrm{r}- \\
153 \mathrm{v}\end{array}$ & Otra a nuestra seráfica madre & Quien isiera de Teresa & $\begin{array}{l}\text { Grandes el mundo } \\
\text { alumbran. Fin. }\end{array}$ & & \\
\hline 89 & $\begin{array}{l}176 \mathrm{v} \text { (al } \\
\text { revés) }\end{array}$ & $\begin{array}{l}\text { A nuestra madre santa Teresa. } \\
\text { Cuartillas }\end{array}$ & $\begin{array}{l}\text { Con asombro del } \\
\text { profundo }\end{array}$ & Con ojos de linze y... & & $\begin{array}{l}\text { Teresa de Sant } \\
\text { Josep, Bojons Sala }\end{array}$ \\
\hline \multirow[t]{2}{*}{90} & $\begin{array}{l}177 \mathrm{r} \text { (al } \\
\text { revés) }\end{array}$ & [Jaculatòries] & & & & $16^{2}$ mà \\
\hline & 2 ff.s.n. & $\begin{array}{l}\text { Tabla de lo que se contiene en } \\
\text { este libro }\end{array}$ & & & & $6^{\mathrm{a}} \mathrm{mà}$ \\
\hline
\end{tabular}

SCRIPTA, Revista internacional de literatura i cultura medieval i moderna, núm. 7 / juny 2016 / pp. 187 - 219

ISSN: 2340-4841 $\cdot$ doi:10.7203/SCRIPTA.7.8476 